\title{
Synthesis of the C(26)-C(42) and C(43)-C(67) Pyran Containing Fragments of Amphidinol 3 via a Common Pyran Intermediate
}

\author{
Jacqueline D. Hicks, and William R. Roush* \\ Department of Chemistry, Scripps Florida, Jupiter, FL 33458 \\ Email: roush@scripps.edu
}

Supporting Information

Part 1 (pages SI-2 to SI-4)

Figure SI-1. Examination of deprotection conditions for polyene 4.

Scheme SI-1. Preparation of Cyclopentylidine Ketal Protected

Polyene 7 and Deprotection

Scheme SI-2. Synthesis of Common Pyran 3.

Part 2 - Experimental Procedures (pages SI-5 to SI-25) 


\section{Part I}

Figure SI-1. Deprotection of SI-1 and examination of deprotection conditions for polyene 4.

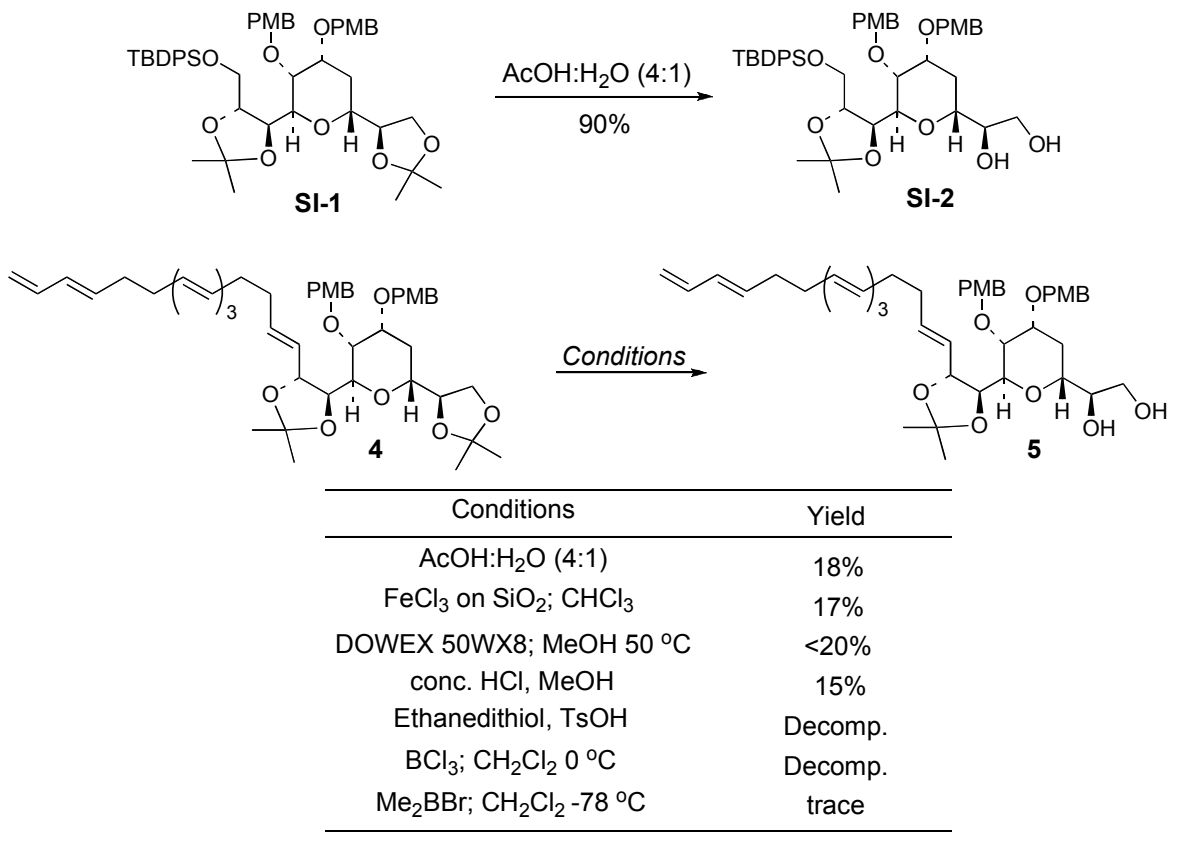

Removal of the terminal acetonide of pyran SI-1 was readily achieved using AcOH: $\mathrm{H}_{2} \mathrm{O}$ (4:1) to provide diol SI-2. However, we were unable to efficiently deprotect polyene $\mathbf{4}$ under various conditions. 
Scheme SI-1. Preparation of Cyclopentylidine Ketal Protected Polyene 7 and Deprotection
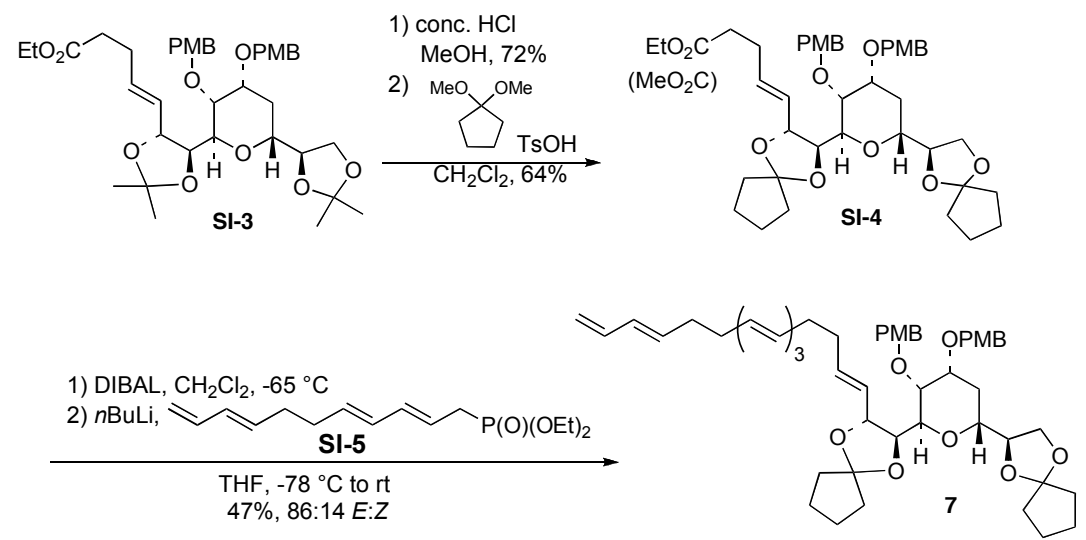

Polyene 7 was rapidly prepared from bis-acetonide SI-3. ${ }^{1}$ Deprotection of the acetonides in acidic methanol followed by reprotection with 1,1-Dimethoxycyclopentane provided ketal SI4. Some transesterfication of the ethyl ester occurred under the acidic methanol conditions. Reduction of ester SI-4 to the aldehyde and Wittig homologation provided polyene 7. 
Scheme SI-2. Synthesis of Common Pyran 3.

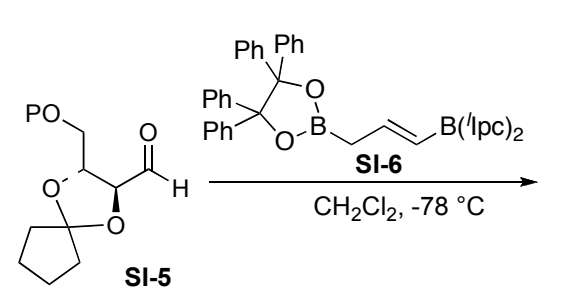

SI-5
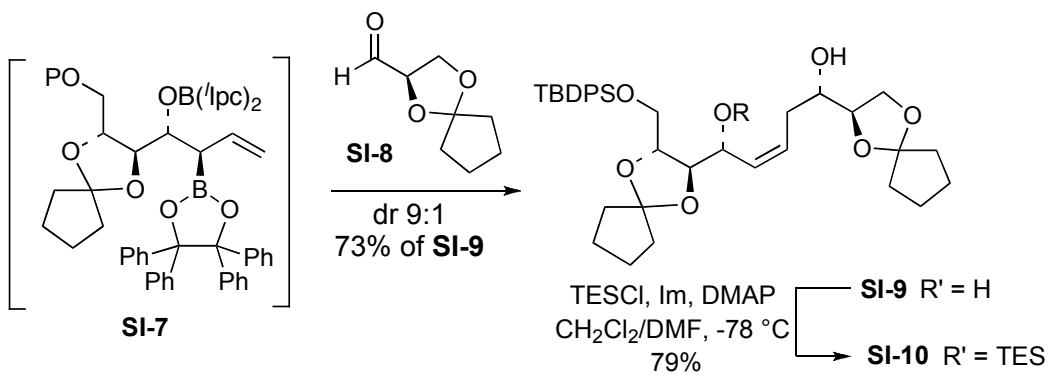

1) $\mathrm{KOt}-\mathrm{Bu}$

t-amylalcohol, $78 \%$

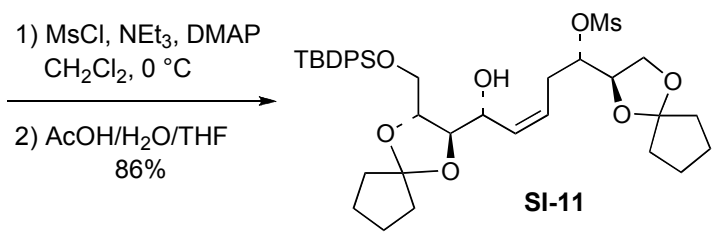

2) $\mathrm{K}_{2} \mathrm{OsO}_{2}(\mathrm{OH})_{4}$, DHQD-IND $\mathrm{K}_{2} \mathrm{CO}_{3}, \mathrm{~K}_{3} \mathrm{FeCN}_{6}, t-\mathrm{BuOH} / \mathrm{H}_{2} \mathrm{O}$ TBDPSO TBSO

quant. $3: 1 \mathrm{dr}, 74 \%$ of desired

3) TBS-OTf, 2.6-lut. $\mathrm{CH}_{2} \mathrm{Cl}_{2}, 89 \%$

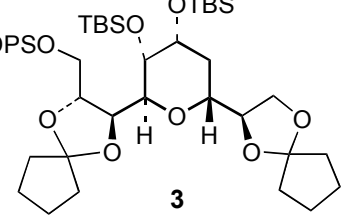

Common pyran intermediate $\mathbf{3}$ was synthesized via slight modification of our previously published route. ${ }^{1}$ Double allylboration reaction between aldehydes SI-5 and SI-8 provided 1,5diol SI-9 with 9:1 diastereoselectivity and 73\% isolated yield of the major diastereomer. Low temperature silylation provided selective protection of the allylic position ${ }^{2}$ and subsequent functionalization provided hydroxy-meyslate SI-9. Base-mediated cyclization, followed by dihydroxylation and protection provided common pyran intermediate 3 . 


\section{Part II}

General Methods. All reaction solvents were purified before use. $\mathrm{CH}_{2} \mathrm{Cl}_{2}, \mathrm{Et}_{2} \mathrm{O}$, toluene, and THF were purified by passing through a solvent column composed of activated alumina (A1). Unless otherwise indicated, all chemicals were used as purchased without further purification. All reactions were conducted under a dry nitrogen atmosphere using oven dried $\left(140{ }^{\circ} \mathrm{C}\right)$ glassware. Removal of solvents was accomplished on a rotary evaporator at reduced pressure. Absolute configurations were determined using the modified Mosher method. ${ }^{3}$

Physical Properties and Spectroscopic Measurements: ${ }^{1} \mathrm{H}$ NMR spectra were recorded on commercial instruments at $400 \mathrm{MHz}$ or $500 \mathrm{MHz} .{ }^{13} \mathrm{C} \mathrm{NMR}$ spectra were recorded on commercial instruments at $100 \mathrm{MHz}$ or $125 \mathrm{MHz}$. The proton signal of residual, non-deuterated solvent $\left(\delta 7.26\right.$ for $\mathrm{CHCl}_{3}$ ) was used as an internal reference for ${ }^{1} \mathrm{H}$ spectra. For ${ }^{13} \mathrm{C}$ spectra, the chemical shifts are reported relative to the $\delta 77.0$ resonance of $\mathrm{CDCl}_{3}$. Coupling constants are reported in Hertz (Hz). Infrared (IR) spectra were recorded as thin films using $\mathrm{CHCl}_{3}$ as the solvent on an FTIR instrument. Optical rotations were measured using a quartz cell with $1 \mathrm{~mL}$ or $0.5 \mathrm{ml}$ capacity and a $10 \mathrm{~cm}$ path length. Mass spectra were recorded on a VG 70-250-s spectrometer manufactured by Micromass Corp. (Manchester UK) at the University of Michigan Mass Spectrometry Laboratory or the Bruker APEX II 4.7 T Fourier Transform Ion Cyclone Resonance mass spectrometer (Bruker Daltonics, Billerica, MA) at the University of Florida Mass Spectrometry Laboratory.

Analytical thin layer chromatography (TLC) was performed on Kieselgel 60 F254 glass plates precoated with a $0.25 \mathrm{~mm}$ thickness of silica gel. TLC plates were visualized with UV light and/or by staining with cerium molybdate $\left(5 \mathrm{~g} \mathrm{Ce}\left(\mathrm{SO}_{4}\right)_{2}, 25 \mathrm{~g}\left(\mathrm{NH}_{4}\right) \mathrm{Mo}_{7} \mathrm{O}_{24} \bullet 4 \mathrm{H}_{2} \mathrm{O}, 450 \mathrm{~mL}\right.$ $\mathrm{H}_{2} \mathrm{O}, 50 \mathrm{~mL} \mathrm{H}_{2} \mathrm{SO}_{4}$ ). Column chromatography was generally performed according to the method of Still using Kieselgel 60 (230-400 mesh) silica gel. ${ }^{4}$

HPLC purifications were using a HPLC system composed of two Varian Prostar pumps (model 210) connected to normal phase columns. Samples were loaded into the Varian system with a $2 \mathrm{~mL}$ Rheodyne 7125 injector and were detected using a Varian Prostar UV or a Varian RI detector. 


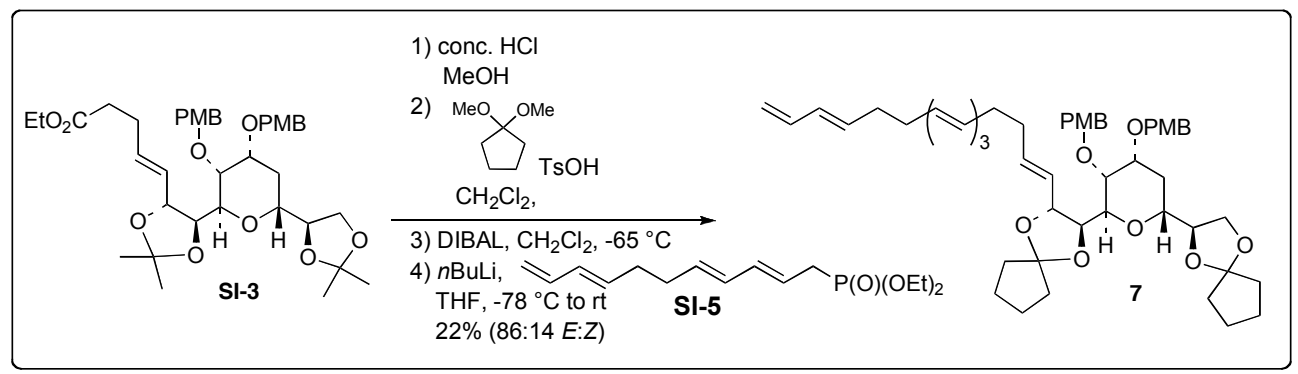

$(2 R, 3 R, 4 R, 6 R)-2-((2 S, 3 R)-3-((1 E, 5 E, 7 E, 9 E, 13 E)$-hexadeca-1,5,7,9,13,15-hexaenyl)-1,4dioxaspiro[4.4]nonan-2-yl)-3,4-(4-methoxybenzyloxy)-6-((R)-1,4-dioxaspiro[4.4]nonan-2yl)tetrahydro-2H-pyran-3-ol (7). To a solution of concentrated $\mathrm{HCl}(450 \mu \mathrm{L})$ in $\mathrm{MeOH}(45$ $\mathrm{mL})$ was added a solution of bis-acetonide $\mathbf{S I}^{1}{ }^{1}(263 \mathrm{mg}, 0.38 \mathrm{mmol})$ in $\mathrm{MeOH}(17 \mathrm{~mL})$. The reaction was monitored by TLC and upon completion quenched with amberlite IRA-400 resin $(15 \mathrm{~g})$. The reaction mixture was filtered and concentrated in vacuo. The resulting oil was purified by flash column chromatography $\left(\mathrm{CH}_{2} \mathrm{Cl}_{2}\right.$ to $1 \% \mathrm{MeOH}$ in $\left.\mathrm{CH}_{2} \mathrm{Cl}_{2}\right)$ to give the tetraol (167 mg, 72\%). To a solution of tetraol $(133 \mathrm{mg}, 0.22 \mathrm{mmol})$ in $\mathrm{CH}_{2} \mathrm{Cl}_{2}$ cooled to $0{ }^{\circ} \mathrm{C}$ was added p-toluenesulfonic acid (6 mg, $0.03 \mathrm{mmol})$ and 1,1-dimethyoxycyclopentane $(350 \mu \mathrm{L})$. The reaction was stirred $1 \mathrm{~h}$ at $0{ }^{\circ} \mathrm{C}$ then diluted with $\mathrm{Et}_{2} \mathrm{O}$ and sat. $\mathrm{NaHCO}_{3}$. The aqueous phase was extracted with EtOAc $(2 x)$, and the combine organic extracts were washed with brine, dried over $\mathrm{Na}_{2} \mathrm{SO}_{4}$, filtered and concentrated in vacuo. The resulting oil was purified by flash column chromatography (30\% EtOAc-hexane) to provide the bis-cyclopentylidene ketal (97 mg, 64\%). To a $-78{ }^{\circ} \mathrm{C}$ solution of bis-cyclopentylidene ketal $(120 \mathrm{mg}, 0.17 \mathrm{mmol})$ in $\mathrm{CH}_{2} \mathrm{Cl}_{2}(1 \mathrm{~mL})$ was added dropwise DIBAL (170 $\mu \mathrm{L}, 0.17 \mathrm{mmol}, 1 \mathrm{M}$ in toluene). The reaction was allowed to stir for $1 \mathrm{~h}$ at $-78^{\circ} \mathrm{C}$, then EtOAc $(200 \mu \mathrm{L})$ was added. The mixture was stirred an additional 10 min, and then diluted with saturated sodium potassium tartrate solution and allowed to warm to ambient temperature and stirred overnight. The biphasic mixture was diluted with $\mathrm{CH}_{2} \mathrm{Cl}_{2}$, and the aqueous phase was extracted with $\mathrm{CH}_{2} \mathrm{Cl}_{2}(2 \mathrm{x})$. The combine organic extracts were washed with brine, dried over $\mathrm{Na}_{2} \mathrm{SO}_{4}$, filtered and concentrated in vacuo. The resulting oil was purified by flash column chromatography (35\% EtOAc-hexane) to give the aldehyde (117 mg, quant.). To a $-78{ }^{\circ} \mathrm{C}$ solution of phosphonate SI-5 $^{1}$ (35 $\left.\mathrm{mg}, 0.12 \mathrm{mmol}\right)$ in THF (250 $\left.\mu \mathrm{L}\right)$ was added dropwise n-BuLi (49 $\mu \mathrm{L}, 2.4 \mathrm{M}$ in hexanes). The solution was stirred for $20 \mathrm{~min}$ at $-78^{\circ} \mathrm{C}$, after which time a solution of aldehyde (48 $\mathrm{mg}, 0.07 \mathrm{mmol})$ in THF $(500 \mu \mathrm{L})$ was added dropwise via syringe pump. The reaction mixture was warmed to $-50{ }^{\circ} \mathrm{C}$ and then slowly warmed to ambient 
temperature. The reaction was stirred for $18 \mathrm{~h}$, diluted with $\mathrm{CH}_{2} \mathrm{Cl}_{2}$ and sat. $\mathrm{NH}_{4} \mathrm{Cl}$, and the aqueaus phase was extrated $(2 \mathrm{x})$ with EtOAc. The combine organic extracts were washed with brine, dried over $\mathrm{Na}_{2} \mathrm{SO}_{4}$, filtered, and concentrated. The resulting crude material was purified by column chormatography (20\% EtOAc:hexane) to give the title compound as a light yellow oil as an 86:14 mixture of $E: Z$ isomers (25 mg, 47\%): $[\alpha]_{\mathrm{D}}{ }^{27}=+0.54\left(c 0.18, \mathrm{CHCl}_{3}\right) ;{ }^{1} \mathrm{H}$ NMR (400 $\left.\mathrm{MHz}, \mathrm{CDCl}_{3}\right) \delta 7.30(\mathrm{~d},, J=8.4 \mathrm{~Hz}, 2 \mathrm{H}), 7.24(\mathrm{~d}, J=8.4 \mathrm{~Hz}, 2 \mathrm{H}), 6.86(\operatorname{app~t}, J=7.2 \mathrm{~Hz}, 4 \mathrm{H})$, $6.30(\mathrm{dt}, J=16.8,10.0 \mathrm{~Hz}, 1 \mathrm{H}), 6.08-5.98(\mathrm{~m}, 5 \mathrm{H}), 5.76-5.60(\mathrm{~m}, 4 \mathrm{H}), 5.47$ (dd, $J=15.6,7.2$ $\mathrm{Hz}, 1 \mathrm{H}), 5.10(\mathrm{~d}, J=16.8 \mathrm{~Hz}, 1 \mathrm{H}), 4.97$ (d, $J=10.0 \mathrm{~Hz}, 1 \mathrm{H}), 4.65$ (A of ABq, $J=12.0 \mathrm{~Hz}, 1 \mathrm{H})$, $4.61(\mathrm{~B}$ of $\mathrm{ABq}, J=12.4 \mathrm{~Hz}, 1 \mathrm{H}), 4.46(\mathrm{~A}$ of $\mathrm{ABq}, J=11.6 \mathrm{~Hz}, 1 \mathrm{H}), 4.42(\mathrm{~B}$ of $\mathrm{ABq}, J=12.0$ Hz, 1H), 4.10-4.03 (m, 2H), 3.98-3.85 (m, 4H), 3.80 (s, 3H), 3.79 (s, 3H), 3.76-3.61 (m, 3H), 2.18-2.05 (m, 8H), 1.90-1.52 (m, 18H); $\left.{ }^{13} \mathrm{C} \mathrm{NMR} \mathrm{(125} \mathrm{MHz,} \mathrm{CDCl}_{3}\right) \delta 159.2,137.2,134.7$, $134.3,133.5,133.2,131.4,131.1,131.0,130.94,130.88,130.7,130.5,129.6,129.1,127.7$, $119.4,119.3,115.1,113.8,113.7,80.77,79.2$, 73.0, 72.6, 71.7, 71.1, 69.7, 65.2, 55.28, 55.26, $37.3,37.2,36.4,36.0,32.5,32.3,32.14,32.05,27.1,23.8,23.6,23.5,23.4$; IR (thin film) 2925 , 1513, $1247 \mathrm{~cm}^{-1}$; HRMS (ESI) calcd for $\mathrm{C}_{51} \mathrm{H}_{66} \mathrm{O}_{9} \mathrm{Na} 713.3666 \mathrm{~m} / z(\mathrm{M}+\mathrm{Na})^{+}$; observed 713.3681 $m / z$.

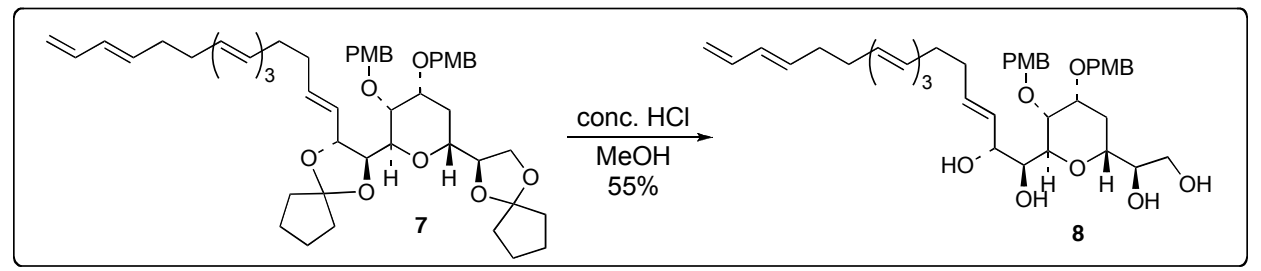

$(1 S, 2 R, 3 E, 7 E, 9 E, 11 E, 15 E)-1-((2 S, 3 R, 4 R, 6 R)-6-((R)-1,2-d i h y d r o x y e t h y l)-3-h y d r o x y-3,4-(4-$ methoxybenzyloxy)tetrahydro-2H-pyran-2-yl)octadeca-3,7,9,11,15,17-hexaene-1,2-diol (8).

To a solution of concentrated $\mathrm{HCl}(25 \mu \mathrm{L})$ in $\mathrm{MeOH}(2.5 \mathrm{~mL})$ was added a solution of polyene 7 $(5 \mathrm{mg}, 0.006 \mathrm{mmol})$ in $\mathrm{MeOH}(1 \mathrm{~mL})$. The reaction was stirred at $\mathrm{rt}$ until complete by TLC $(\sim 0.5 \mathrm{~h})$ then quenched with Amberlite IRA 400 and $\mathrm{K}_{2} \mathrm{CO}_{3}$ untill basic. The reaction mixture was filtered through a cotton plug and concentrated in vacuo. The resulting oil was purified by column chromatography ( $80 \%$ to $90 \%$ EtOAc:Hex) to provide the title compound (2.3 $\mathrm{mg}$, 55\%): ${ }^{1} \mathrm{H}$ NMR (400 MHz, $\left.\mathrm{CDCl}_{3}\right) \oint 7.25$ (d, $\left.J=9.2 \mathrm{~Hz}, 2 \mathrm{H}\right), 7.22$ (d, $\left.J=8.4 \mathrm{~Hz}, 2 \mathrm{H}\right), 6.89-$ $6.85(\mathrm{~m}, 4 \mathrm{H}), 6.30(\mathrm{dt}, J=16.8,10.4 \mathrm{~Hz}, 1 \mathrm{H}), 6.13-6.03(\mathrm{~m}, 5 \mathrm{H}), 5.78-5.62(\mathrm{~m}, 5 \mathrm{H}), 5.10(\mathrm{~d}, J$ $=16.8 \mathrm{~Hz}, 1 \mathrm{H}), 4.97(\mathrm{~d}, J=10.0 \mathrm{~Hz}, 1 \mathrm{H}), 4.57$ (A of ABq, $J=11.2 \mathrm{~Hz}, 1 \mathrm{H}), 4.53-4.32(\mathrm{~m}, 2 \mathrm{H})$, $4.38-4.32(\mathrm{~m}, 3 \mathrm{H}), 4.03-3.98(\mathrm{~m}, 2 \mathrm{H}), 3.81(\mathrm{~s}, 3 \mathrm{H}), 3.80(\mathrm{~s}, 3 \mathrm{H}), 3.79-3.76(\mathrm{~m}, 3 \mathrm{H}), 3.76-3.64$ 
(m, 2H), 3.54-3.49 (m, 1H), $3.21(\mathrm{~d}, J=2.4 \mathrm{~Hz}, 1 \mathrm{H}), 2.25-2.01(\mathrm{~m}, 11 \mathrm{H}), 1.79$ (br d, $J=14.8$ $\mathrm{Hz}, 1 \mathrm{H}) ;{ }^{13} \mathrm{C}$ NMR $\left(100 \mathrm{MHz}, \mathrm{CDCl}_{3}\right) \delta 159.5,159.4,137.2,134.4,133.4,133.3,132.8,131.4$, 131.1, 131.0, 130.9, 130.0, 129.6, 129.5, 129.4, 129.3, 115.0, 114.0, 113.9, 74.6, 72.7, 71.5, 71.2, 70.5, 70.3, 69.2, 55.3, 32.5, 32.4, 32.1, 28.7; IR (thin film) 3368, 2917, $1511 \mathrm{~cm}^{-1}$; HRMS (ESI) calcd for $\mathrm{C}_{41} \mathrm{H}_{54} \mathrm{O}_{9} \mathrm{Na} 713.3660 \mathrm{~m} / z(\mathrm{M}+\mathrm{Na})^{+}$; observed $845.4621 \mathrm{~m} / \mathrm{z}$.

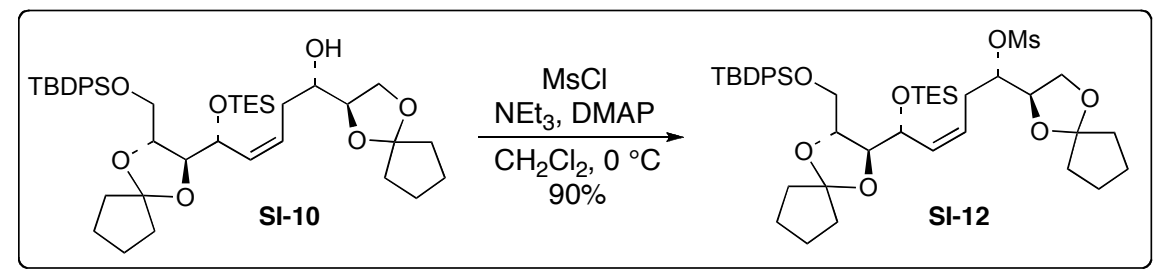

$(1 S, 5 R, Z)-5-((2 S, 3 R)-3-((t e r t-b u t y l d i p h e n y l s i l y l o x y) m e t h y l)-1,4-$

dioxaspiro[4.4]nonan-2-yl)-1-((R)-1,4-dioxaspiro[4.4]nonan-2-yl)-5-(triethylsilyloxy)pent-3enyl methanesulfonate (SI-12). To a $0{ }^{\circ} \mathrm{C}$ solution of alcohol SI-10 ${ }^{2}(28.5 \mathrm{~g}, 38.6 \mathrm{mmol})$, triethylamine (27.1 mL, $195 \mathrm{mmol})$, and DMAP (470 mg, $3.8 \mathrm{mmol})$ in $\mathrm{CH}_{2} \mathrm{Cl}_{2}(380 \mathrm{~mL})$ was added methanesulfonyl chloride $(30.0 \mathrm{~mL}, 386 \mathrm{mmol})$. The reaction mixture was stirred for 45 min, then diluted with $\mathrm{CH}_{2} \mathrm{Cl}_{2}$ and aq. $\mathrm{NH}_{4} \mathrm{Cl}$. The organic layer was washed with $1 \mathrm{M} \mathrm{NaOH}$ (x2), sat. $\mathrm{NaHCO}_{3}$, and brine. The extracts were then dried over $\mathrm{Na}_{2} \mathrm{SO}_{4}$, filtered, and concentrated in vacuo. The residue was purified by flash column chromatography ( $20 \%$ EtOAchexanes) to give the title compound as a yellow oil $(28.2 \mathrm{~g}, 90 \%)$ : $[\alpha]_{\mathrm{D}}{ }^{27}=+12.4(c$ 2.8, $\left.\mathrm{CHCl}_{3}\right) ;{ }^{1} \mathrm{H}$ NMR (400 MHz, $\left.\mathrm{CDCl}_{3}\right) \oint 7.73-7.71(\mathrm{~m}, 4 \mathrm{H}), 7.44-7.35(\mathrm{~m}, 6 \mathrm{H}), 5.57-5.47(\mathrm{~m}$, 2H), 4.80 (dd, $J=11.2,5.6 \mathrm{~Hz}, 1 \mathrm{H}), 4.45(\mathrm{t}, J=7.6 \mathrm{~Hz}, 1 \mathrm{H}), 4.13-4.9(\mathrm{~m}, 2 \mathrm{H}), 3.99-3.87(\mathrm{~m}$, $3 \mathrm{H}), 3.78(\mathrm{t}, J=7.2 \mathrm{~Hz}, 1 \mathrm{H}), 3.71(\mathrm{dd}, J=11.2,5.2 \mathrm{~Hz}, 1 \mathrm{H}), 3.05(\mathrm{~s}, 3 \mathrm{H}), 2.62-2.57(\mathrm{~m}, 2 \mathrm{H})$, $1.84-1.62(\mathrm{~m}, 16 \mathrm{H}), 1.06(\mathrm{~s}, 9 \mathrm{H}), 0.93(\mathrm{t}, J=8 \mathrm{~Hz}, 9 \mathrm{H}), 0.56(\mathrm{q}, J=8 \mathrm{~Hz}, 6 \mathrm{H}) ;{ }^{13} \mathrm{C}$ NMR $(100$ $\left.\mathrm{MHz}, \mathrm{CDCl}_{3}\right) \delta 135.7,135.6,134.5,133.50,135.47,129.6,127.6,127.5,124.6,119.6,119.2$, $80.8,79.8,79.2,77.2,75.6,69.7,65.2,65.0,38.7,37.3,37.1,36.2,35.8,30.5,26.8,23.6,23.4$, 23.33, 23.26, 19.3, 6.8, 4.9; IR (thin film) 2957, 1336, $1112 \mathrm{~cm}^{-1}$; HRMS (ESI) calcd for $\mathrm{C}_{43} \mathrm{H}_{66} \mathrm{O}_{9} \mathrm{SSi}_{2} \mathrm{Na} 837.3864 \mathrm{~m} / z(\mathrm{M}+\mathrm{Na})^{+}$; observed $837.3860 \mathrm{~m} / \mathrm{z}$.

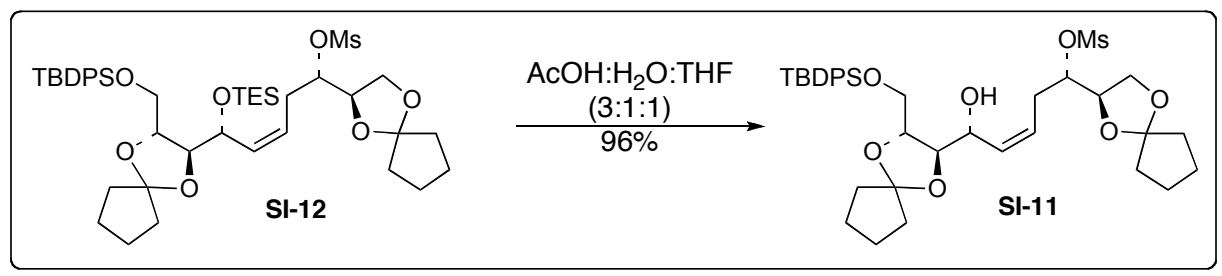




\section{(1S,5R,Z)-5-((2R,3R)-3-((tert-butyldiphenylsilyloxy)methyl)-1,4-}

\section{dioxaspiro[4.4]nonan-2-yl)-5-hydroxy-1-((R)-1,4-dioxaspiro[4.4]nonan-2-yl)pent-3-enyl}

methanesulfonate (SI-11) A mixture of silyl ether SI-12 (21.6g, $26.5 \mathrm{mmol})$, acetic acid (125 $\mathrm{mL})$, water (42 mL), and THF (42 $\mathrm{mL}$ ) was stirred at ambient temperature until the reaction was judged complete by TLC analysis (1 h). The reaction mixture was diluted with EtOAc (1L) and neutralized with $\mathrm{NaOH}(1.1 \mathrm{~L}, 3 \mathrm{M})$. The biphasic mixture was separated and the organic layer was washed with $\mathrm{NaOH}(3 \mathrm{M})$, sat. $\mathrm{NaHCO}_{3}$, and brine; then dried over $\mathrm{Na}_{2} \mathrm{SO}_{4}$, filtered and concentrated in vacuo. The resulting oil was purified by flash column chromatography (25\% EtOAc-hexane to 35\% EtOAc-hexane) to give the title compound as a white foam (17.8g, 96\%): $[\alpha]_{\mathrm{D}}{ }^{27}=-14.3\left(c\right.$ 2.8, $\left.\mathrm{CHCl}_{3}\right) ;{ }^{1} \mathrm{H}$ NMR $\left(400 \mathrm{MHz}, \mathrm{CDCl}_{3}\right) \oint 7.69-7.65(\mathrm{~m}, 4 \mathrm{H}), 7.46-7.37$ (m, 6H), 5.69-5.60 (m, 2H), $4.78(\mathrm{dd}, J=11.2,5.6 \mathrm{~Hz}, 1 \mathrm{H}), 4.51-4.47(\mathrm{~m}, 1 \mathrm{H}), 4.02$ (td, $J=6,4.4$ $\mathrm{Hz}, 1 \mathrm{H}), 3.98-3.86(\mathrm{~m}, 3 \mathrm{H}), 3.80$ (dd, $J=10.8,4.4 \mathrm{~Hz}, 1 \mathrm{H}), 3.73$ (dd, $J=10.8,6 \mathrm{~Hz}, 1 \mathrm{H}), 3.04$ $(\mathrm{s}, 3 \mathrm{H}), 2.83(\mathrm{~d}, J=2.8 \mathrm{~Hz}, 1 \mathrm{H}), 2.71-2.57(\mathrm{~m}, 2 \mathrm{H}), 1.86-1.61(\mathrm{~m}, 16 \mathrm{H}), 1.06(\mathrm{~s}, 9 \mathrm{H}) ;{ }^{13} \mathrm{C} \mathrm{NMR}$ $\left(100 \mathrm{MHz}, \mathrm{CDCl}_{3}\right) \delta 135.59,135.57,132.73,132.68,132.1,129.9,129.8,127.8,127.0,119.7$, $119.2,80.9,80.6,78.5,77.2,75.1,67.8,65.3,64.8,38.7,37.2,37.0,36.1,35.8,30.2,26.8,23.6$, 23.5, 23.24, 23.21, 19.1; IR (thin film) 3468, 2959, 1336, $1112 \mathrm{~cm}^{-1}$; HRMS (ESI) calcd for $\mathrm{C}_{37} \mathrm{H}_{52} \mathrm{O}_{9} \mathrm{SSiNa} 723.2999 \mathrm{~m} / z(\mathrm{M}+\mathrm{Na})^{+}$; observed $723.3004 \mathrm{~m} / z$.

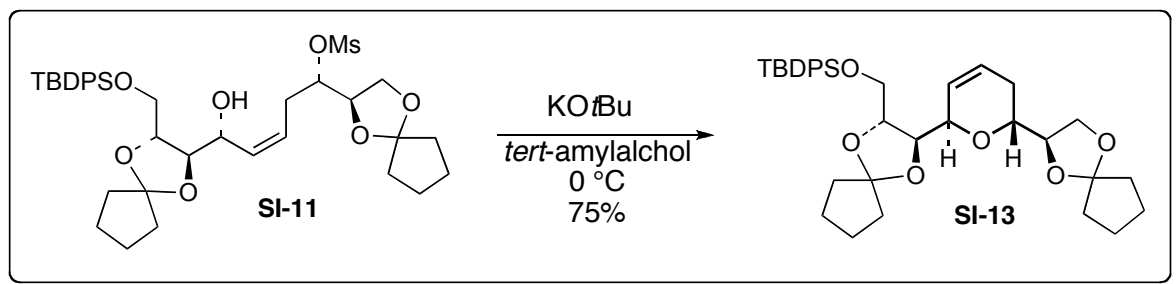

$(((2 R, 3 R)-3-((2 R, 6 R)-6-((R)-1,4-d i o x a s p i r o[4.4]$ nonan-2-yl)-5,6-dihydro-2H-pyran-2yl)-1,4-dioxaspiro[4.4]nonan-2-yl)methoxy)(tert-butyl)diphenylsilane $\quad$ (SI-13). $\quad$ To a suspension of $\mathrm{KO} t \mathrm{Bu}(4.08 \mathrm{~g}, 36.4 \mathrm{mmol})$ in $t$-amyl alcohol $(500 \mathrm{~mL})$ was added dropwise a solution of homoallylic mesylate SI-11 (17 g, $24.2 \mathrm{mmol})$ in $t$-amyl alcohol $(250 \mathrm{~mL})$. The mixture was stirred for $1 \mathrm{~h}$, then was diluted with EtOAc and washed with sat. $\mathrm{NaHCO}_{3}$. The aqueous phase was then extracted with EtOAc (3x), and the combine organics were washed with brine, dried over $\mathrm{Na}_{2} \mathrm{SO}_{4}$, filtered and concentrated in vacuo. The resulting oil was purified by flash column chromatography (10\% EtOAc-hexane) to give the title compound as a clear oil $\left.(11.0 \mathrm{~g}, 75 \%):[\alpha]_{\mathrm{D}}{ }^{27}=+74.9(c) 1.6, \mathrm{CHCl}_{3}\right) ;{ }^{1} \mathrm{H} \mathrm{NMR}\left(400 \mathrm{MHz}, \mathrm{CDCl}_{3}\right) \delta 7.73-7.69(\mathrm{~m}$, 4H), 7.43-7.35 (m, 6H), 5.95 (ddt, $J=10.4,4.8,2.4 \mathrm{~Hz}, 1 \mathrm{H}), 5.90$ (dt, $J=10.8,1.6 \mathrm{~Hz}, 1 \mathrm{H})$, 
4.14 (br d, $J=7.2 \mathrm{~Hz}, 1 \mathrm{H}), 4.09$ (ddd, $J=8.4,4.8,3.6 \mathrm{~Hz}, 1 \mathrm{H}), 4.03-3.90$ (m, 3H), 3.84-3.71 $(\mathrm{m}, 4 \mathrm{H}), 2.05-1.94(\mathrm{~m}, 2 \mathrm{H}), 1.82-1.55(\mathrm{~m}, 16 \mathrm{H}), 1.06(\mathrm{~s}, 9 \mathrm{H}) ;{ }^{13} \mathrm{C} \mathrm{NMR}\left(100 \mathrm{MHz}, \mathrm{CDCl}_{3}\right) \delta$ $135.7,133.6,133.5,129.64,129.63,127.6,126.6,124.8,119.5,119.3,80.5,78.3,77.3,76.6$, 73.7, 69.7, 65.1, 64.5, 37.7, 37.4, 36.2, 36.0, 26.9, 25.1, 23.7, 23.6, 23.5, 23.3, 19.3; IR (thin film) 2932, 1334, $1106 \mathrm{~cm}^{-1}$; HRMS (ESI) calcd for $\mathrm{C}_{36} \mathrm{H}_{48} \mathrm{O}_{6} \mathrm{SiNa} 627.3118 \mathrm{~m} / z(\mathrm{M}+\mathrm{Na})^{+}$; observed $627.3118 \mathrm{~m} / \mathrm{z}$.

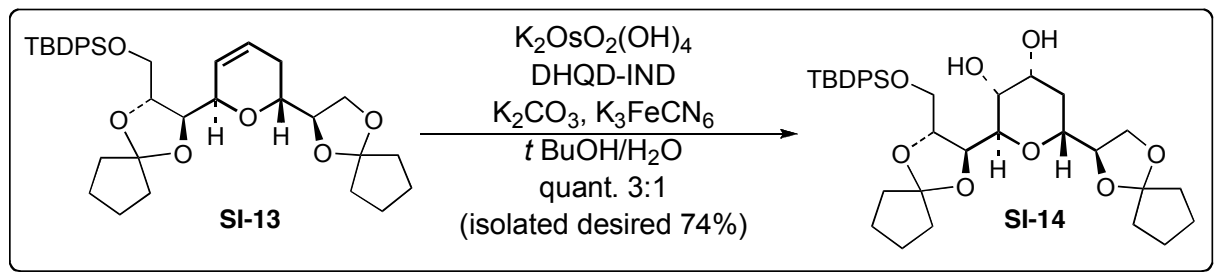

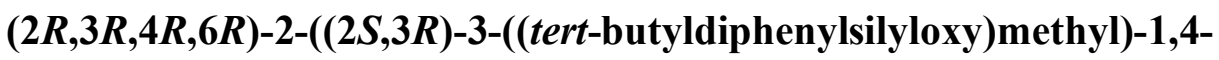

dioxaspiro[4.4]nonan-2-yl)-6-((R)-1,4-dioxaspiro[4.4] nonan-2-yl)tetrahydro-2H-pyran-3,4-

diol (SI-14). To a $0{ }^{\circ} \mathrm{C}$ solution of dihydropyran SI-13 (11 g, $\left.18.2 \mathrm{mmol}\right)$ in $t$-BuOH $(270 \mathrm{~mL})$ and water $(270 \mathrm{~mL})$ was added methanesulfonamide $(3.1 \mathrm{~g}, 32.7 \mathrm{mmol})$ and $28 \mathrm{~g}$ of a stock mixture composed of $\mathrm{K}_{3} \mathrm{FeCN}_{6}(474 \mathrm{~g}), \mathrm{K}_{2} \mathrm{CO}_{3}(201 \mathrm{~g}), \mathrm{K}_{2} \mathrm{OsO}_{2}(\mathrm{OH})_{4}(690 \mathrm{mg})$, DHQD-Ind ligand $^{7}$ (4.26 g). The reaction mixture was stirred for $24 \mathrm{~h}$, then $\mathrm{Na}_{2} \mathrm{~S}_{2} \mathrm{O}_{3}(190 \mathrm{~g})$ was added and the resulting solution was stirred for $2 \mathrm{~h}$, after which it was diluted with EtOAc and water. The biphasic mixture was separated and the aqueous phase was extracted with EtOAc $(3 \mathrm{x})$. The combined organic layers were washed with $1 \mathrm{~N} \mathrm{KOH}$, sat. $\mathrm{NaHCO}_{3}$, and brine, dried over $\mathrm{Na}_{2} \mathrm{SO}_{4}$, filtered, and concentrated in vacuo. The resulting foam (3:1 mixture of diastereomers) was purified by flash column chromatography (50\% EtOAc: hexane) to give the major diasteromer SI-14 (8.6g, 74\%): $[\alpha]_{\mathrm{D}}{ }^{27}=+72.8\left(c\right.$ 0.7, $\left.\mathrm{CHCl}_{3}\right) ;{ }^{1} \mathrm{H}$ NMR $\left(400 \mathrm{MHz}, \mathrm{CDCl}_{3}\right) \delta$ 7.72-7.69 (m, 4H), 7.44-7.34 (m, 6H), 4.45 (dd, $J=13.6,6.4$ Hz, 1H), 4.15-4.06 (m, 3H), 3.96$3.97(\mathrm{~m}, 2 \mathrm{H}), 3.84-3.73(\mathrm{~m}, 3 \mathrm{H}), 3.68(\mathrm{dt}, J=7.6,5.2 \mathrm{~Hz}, 1 \mathrm{H}), 3.62(\mathrm{dd}, J=8.0,6.0 \mathrm{~Hz}, 1 \mathrm{H})$, $3.25(\mathrm{~d}, J=3.2 \mathrm{~Hz}, 1 \mathrm{H}), 2.78(\mathrm{~d}, J=4.4 \mathrm{~Hz}, 1 \mathrm{H}), 1.92-1.57(\mathrm{~m}, 18 \mathrm{H}), 1.06(\mathrm{~s}, 9 \mathrm{H}) ;{ }^{13} \mathrm{C}$ NMR $\left(100 \mathrm{MHz}, \mathrm{CDCl}_{3}\right) \delta 135.7,133.6,133.4,129.6,127.6,119.9,119.5,81.4,75.4,72.8,71.8,70.3$, $66.0,65.6,63.8,37.4,37.2,36.5,36.2,30.4,26.8,23.6,23.5,23.4,23.2,19.3$; IR (thin film) 3436, 2958, 1335, $1111 \mathrm{~cm}^{-1}$; HRMS (ESI) calcd for $\mathrm{C}_{36} \mathrm{H}_{50} \mathrm{O}_{8} \mathrm{SiNa} 661.3173 \mathrm{~m} / \mathrm{z}(\mathrm{M}+\mathrm{Na})^{+}$; observed $661.3172 \mathrm{~m} / z$. 


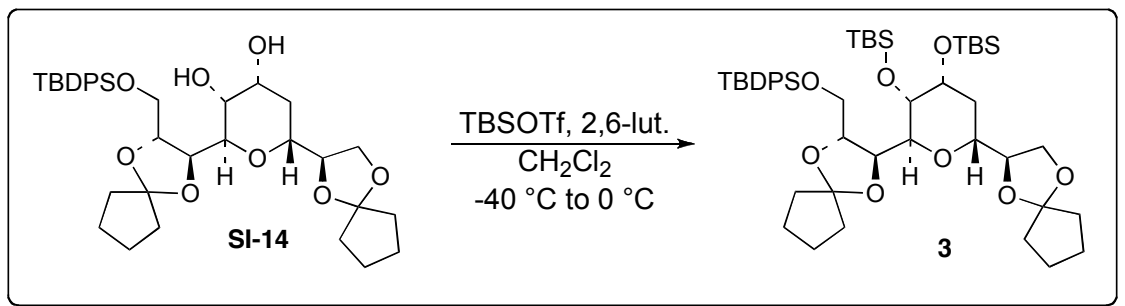

((2S,3S,4R,6R)-2-((2S,3R)-3-((tert-butyldiphenylsilyloxy)methyl)-1,4-

dioxaspiro[4.4]nonan-2-yl)-6-((R)-1,4-dioxaspiro[4.4] nonan-2-yl)tetrahydro-2H-pyran-3,4-

diyl)bis(oxy)bis(tert-butyldimethylsilane) (3). To a solution of diol (4.02g, $6.3 \mathrm{mmol})$ and 2,6lutidine $(1.87 \mathrm{~mL}, 17.0 \mathrm{mmol})$ in $\mathrm{CH}_{2} \mathrm{Cl}_{2}(63 \mathrm{~mL})$ cooled to $-40{ }^{\circ} \mathrm{C}$ was added TBSOTf (3.16 $\mathrm{mL}, 13.8 \mathrm{mmol})$. The reaction was allowed to slowly warm to $\mathrm{rt}$, then was diluted with $\mathrm{CH}_{2} \mathrm{Cl}_{2}$ and quenched with sat. $\mathrm{NaHCO}_{3}$. The aqueous layer was extracted with $\mathrm{CH}_{2} \mathrm{Cl}_{2}(\mathrm{x} 1)$ and the combine organics washed with brine, dried over $\mathrm{Na}_{2} \mathrm{SO}_{4}$, filtered, and concentrated in vacuo. The resulting oil was purified by column chromatography (7\% EtOAc-hexanes) to give the title compound as a clear oil $(4.85 \mathrm{~g}, 89 \%):[\alpha]_{\mathrm{D}}{ }^{25}=+11.9\left(c 1.1, \mathrm{CHCl}_{3}\right) ;{ }^{1} \mathrm{H} \mathrm{NMR}(400 \mathrm{MHz}$, $\left.\mathrm{CDCl}_{3}\right) \oint 7.74(\mathrm{~d}, J=7.6,2 \mathrm{H}), 7.69$ (d, $\left.J=6.4 \mathrm{~Hz}, 2 \mathrm{H}\right), 7.44-7.36(\mathrm{~m}, 6 \mathrm{H}), 4.30$ (dd, $J=10,6.8$ $\mathrm{Hz}, 1 \mathrm{H}), 4.07(\mathrm{dt}, J=10.4,3.6,1 \mathrm{H}), 4.03-4.01(\mathrm{~m}, 2 \mathrm{H}), 3.94(\mathrm{dd}, J=11.2,2.4 \mathrm{~Hz}, 1 \mathrm{H}), 3.89(\mathrm{t}$, $J=6 \mathrm{~Hz}, 1 \mathrm{H}), 3.81(\mathrm{t}, J=8.4,1 \mathrm{H}), 3.77-3.68(\mathrm{~m}, 4 \mathrm{H}), 1.86-1.63(\mathrm{~m}, 17 \mathrm{H}), 1.33(\mathrm{br} \mathrm{d}, J=12.4$ $\mathrm{Hz}, 1 \mathrm{H}), 1.05$ (s, 9H), $0.91(\mathrm{~s}, 9 \mathrm{H}), 0.90(\mathrm{~s}, 9 \mathrm{H}), 0.08(\mathrm{~s}, 6 \mathrm{H}), 0.07(\mathrm{~s}, 3 \mathrm{H}), 0.05(\mathrm{~s}, 3 \mathrm{H}) ;{ }^{13} \mathrm{C}$ NMR (125 MHz, $\left.\mathrm{CDCl}_{3}\right) \oint 135.8,135.7,133.4,133.2,129.7,129.7,127.7,127.6,119.4,119.3$, 81.9, 81.4, 76.9, 72.5, 72.2, 69.6, 67.6, 65.0, 63.4, 37.5, 37.1, 36.1, 36.0, 29.1, 26.9, 26.2, 25.9, 23.9, 23.5, 23.4, 23.2, 19.4, 18.5, 18.2, -4.3, -4.6, -4.8; IR (thin film) 2956, 2857, $1107 \mathrm{~cm}^{-1}$; HRMS (ESI) calcd for $\mathrm{C}_{48} \mathrm{H}_{78} \mathrm{O}_{8} \mathrm{Si}_{3} \mathrm{Na} 889.4902 \mathrm{~m} / \mathrm{z}(\mathrm{M}+\mathrm{Na})^{+}$; observed $889.4910 \mathrm{~m} / \mathrm{z}$; Anal calcd for $\mathrm{C}_{47} \mathrm{H}_{78} \mathrm{O}_{8} \mathrm{Si}_{3}$ : C, 66.47; H, 9.06 . Found: C, 66.61; H, 9.16.

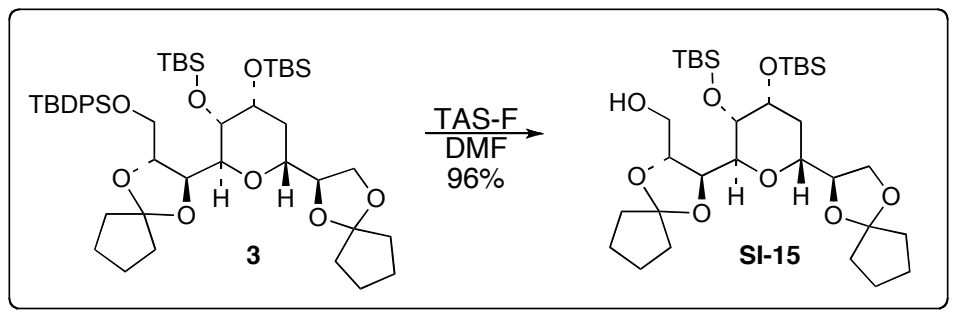

((2R,3S)-3-((2S,3S,4R,6R)-3,4-bis(tert-butyldimethylsilyloxy)-6-((R)-1,4dioxaspiro[4.4]nonan-2-yl)tetrahydro-2H-pyran-2-yl)-1,4-dioxaspiro[4.4]nonan-2yl)methanol (SI-15). To a solution of TBDPS ether $3(0.93 \mathrm{~g}, 1.07 \mathrm{mmol})$ in DMF $(8 \mathrm{~mL})$ cooled to $0{ }^{\circ} \mathrm{C}$ was added a solution of TAS-F (275 mg, $1.33 \mathrm{mmol}, 1.3 \mathrm{M}$ in THF). The 
reaction was monitored by TLC, judged complete after $3 \mathrm{~h}$, then was diluted with EtOAc and quenched with $\mathrm{pH} 7$ buffer. The aqueous layer was extracted with EtOAc (x2) and the combine organics washed with brine, dried over $\mathrm{Na}_{2} \mathrm{SO}_{4}$, filtered, and concentrated in vacuo. The resulting oil was purified by column chromatography (20\% EtOAc-hexanes) to give the title compound as a clear oil (591 mg, 96\%): $[\alpha]_{\mathrm{D}}{ }^{27}=+10.2\left(c 0.87, \mathrm{CHCl}_{3}\right) ;{ }^{1} \mathrm{H}$ NMR $(400 \mathrm{MHz}$, $\left.\mathrm{CDCl}_{3}\right) \delta 4.05-3.93(\mathrm{~m}, 6 \mathrm{H}), 3.86-3.83(\mathrm{~m}, 2 \mathrm{H}), 3.80(\mathrm{~d}, J=10.4 \mathrm{~Hz}, 1 \mathrm{H}), 3.68-3.63(\mathrm{~m}, 2 \mathrm{H})$, $2.02(\mathrm{dd}, J=8.4,4.8 \mathrm{~Hz}, 1 \mathrm{H}), 1.88(\mathrm{q}, J=11.6 \mathrm{~Hz}, 1 \mathrm{H}), 1.86-1.65(\mathrm{~m}, 16 \mathrm{H}), 1.24(\mathrm{br} \mathrm{d}, J=8$ $\mathrm{Hz}, 1 \mathrm{H}), 0.90$ (s, 18H), 0.07 (s, 6H), 0.07 (s, 3H), 0.05 (s, 3H); $\left.{ }^{13} \mathrm{C} \mathrm{NMR} \mathrm{(100} \mathrm{MHz,} \mathrm{CDCl}_{3}\right)$ $\oint 119.7,119.1,82.3,82.0,77.8,37.4,37.0,36.3,35.9,29.6,26.1,25.8,23.7,23.6,23.4,23.2$, $18.4,18.2,-4.4,-4.6$; IR (thin film) 3501, 2929, $1106 \mathrm{~cm}^{-1}$; HRMS (ESI) calcd for $\mathrm{C}_{32} \mathrm{H}_{60} \mathrm{O}_{8} \mathrm{Si}_{2} \mathrm{Na} 651.3724 \mathrm{~m} / \mathrm{z}(\mathrm{M}+\mathrm{Na})^{+}$; observed $651.3723 \mathrm{~m} / \mathrm{z}$.

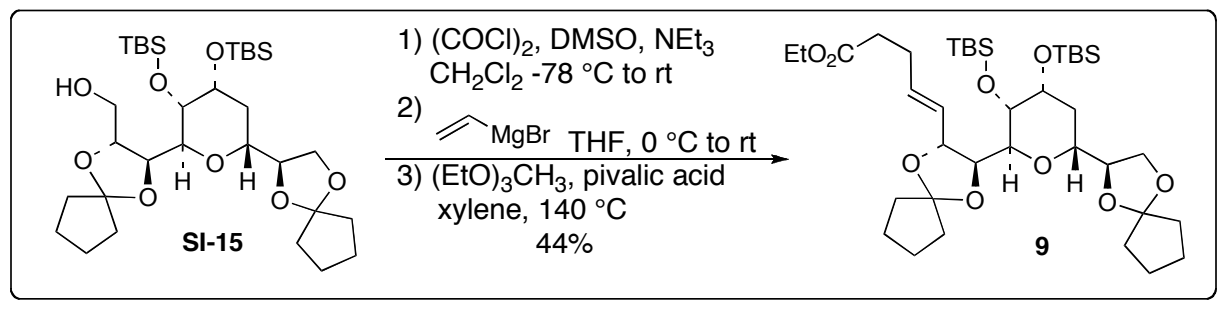

(E)-ethyl-5-((2R,3S)-3-((2S,3S,4R,6R)-3,4-bis(tert-butyldimethylsilyloxy)-6-((R)-1,4dioxaspiro[4.4]nonan-2-yl)tetrahydro-2H-pyran-2-yl)-1,4-dioxaspiro[4.4]nonan-2-yl)pent4-enoate (9). To a $-78{ }^{\circ} \mathrm{C}$ solution of distilled oxalyl chloride $(180 \mu \mathrm{L}, 2.09 \mathrm{mmol})$ in $\mathrm{CH}_{2} \mathrm{Cl}_{2}(1$ $\mathrm{mL})$ was added dropwise a solution of dimethyl sulfoxide $(300 \mu \mathrm{L}, 4.18 \mathrm{mmol})$ in $\mathrm{CH}_{2} \mathrm{Cl}_{2}(1$ $\mathrm{mL})$. The resulting solution was stirred for $5 \mathrm{~min}$ at $-78^{\circ} \mathrm{C}$. A solution of alcohol SI-18 $(1.11 \mathrm{~g}$, $1.9 \mathrm{mmol})$ in $\mathrm{CH}_{2} \mathrm{Cl}_{2}(2 \mathrm{~mL})$ was added and the reaction mixture was allowed to stir $15 \mathrm{~min}$ at $78{ }^{\circ} \mathrm{C}$. Triethylamine $(0.8 \mathrm{~mL}, 5.7 \mathrm{mmol})$ was added, the reaction was warmed to ambient temperature. The reaction mixture was concentrated in vacuo and the resulting white solid was suspended in $\mathrm{Et}_{2} \mathrm{O}$, filtered though Celite, and concentrated in vacuo to give a yellow oil. The crude aldehyde was used directly in the subsequent reaction. ${ }^{1} \mathrm{H}$ NMR $\left(400 \mathrm{MHz}, \mathrm{CDCl}_{3}\right) \oint 9.81$ $(\mathrm{d}, J=0.8 \mathrm{~Hz}, 1 \mathrm{H}), 4.42(\mathrm{~d}, J=5.6 \mathrm{~Hz}, 1 \mathrm{H}), 4.25(\mathrm{dd}, J=10,5.6 \mathrm{~Hz}, 1 \mathrm{H}), 4.05(\mathrm{q}, J=6 \mathrm{~Hz}$, 1H), 3.99-3.90 (m, 3H), 3.79-3.76 (m, 2H), 3.68 (ddd, $J=12.0,6.0,3.6 \mathrm{~Hz}, 1 \mathrm{H}), 1.95$ (q, $J=$ $11.2 \mathrm{~Hz}, 1 \mathrm{H}), 1.84-1.63$ (m, $16 \mathrm{H}), 1.34$ (br d, $J=12.4,1 \mathrm{H}), 0.90$ (s, $16 \mathrm{H}), 0.084$ (s, 3H), 0.078 (s, 3H), 0.07 (s, 3H), 0.06 (s, 3H).

A $0{ }^{\circ} \mathrm{C}$ solution of the crude aldehyde $(1.9 \mathrm{mmol})$ in THF $(5 \mathrm{~mL})$ was treated with vinyl 
magnesium bromide $(3.8 \mathrm{~mL}, 3.8 \mathrm{mmol}, 1 \mathrm{M}$ in THF). The reaction mixture was stirred $15 \mathrm{~min}$ at $0{ }^{\circ} \mathrm{C}$, diluted with sat. $\mathrm{NH}_{4} \mathrm{Cl}$ and EtOAc. The aqueous phase was extracted with EtOAc $(2 \mathrm{x})$, and the combine organic extracts were washed with brine, dried over $\mathrm{Na}_{2} \mathrm{SO}_{4}$, filtered and concentrated in vacuo. The resulting oil was purified by flash column chromatography (15\% EtOAc-hexane) and the crude oil was used directly in the subsequent reaction. A round bottom flask equipped with a short path distillation head and collection flask was charged with the allylic alcohol $(1.9 \mathrm{mmol})$, triethyl orthoacetate $(2.6 \mathrm{~mL}, 15.5 \mathrm{mmol})$, pivalic acid $(8 \mathrm{mg}, 70$ $\mu \mathrm{mol})$, and xylene $(10 \mathrm{~mL})$. This mixture was heated to $140^{\circ} \mathrm{C}$ for $4 \mathrm{~d}$. Upon completion of the reaction by TLC analysis, the mixture was diluted with EtOAc and $1 \mathrm{M} \mathrm{HCl}$, stirred for 15 min, and the organic phase was washed with $1 \mathrm{M} \mathrm{HCl}(2 \mathrm{x})$, sat. $\mathrm{NaHCO}_{3}$, and brine. The combine extracts were dried over $\mathrm{Na}_{2} \mathrm{SO}_{4}$, filtered and concentrated in vacuo. The resulting oil was purified by flash column chromatography (10\% EtOAc-hexane) to give the title compound (602 mg, 44\%): $[\alpha]_{\mathrm{D}}{ }^{27}=+10.9\left(\right.$ c 3.9, $\left.\mathrm{CHCl}_{3}\right) ;{ }^{1} \mathrm{H} \mathrm{NMR}\left(400 \mathrm{MHz}, \mathrm{CDCl}_{3}\right) \oint 5.86$ (br d, J=15.2 Hz, 1H), $5.56(\mathrm{dd}, J=15.2,7.2 \mathrm{~Hz}, 1 \mathrm{H}), 4.24(\mathrm{t}, J=7.2 \mathrm{~Hz}, 1 \mathrm{H}), 4.12$ (q, $J=7.2 \mathrm{~Hz}, 2 \mathrm{H}), 4.05(\mathrm{dt}, J$ = 7.6, $2.8 \mathrm{~Hz}, 1 \mathrm{H}), 3.99$ (q, $5.6 \mathrm{~Hz}, 1 \mathrm{H}), 3.92(\mathrm{br} \mathrm{s}, 1 \mathrm{H}), 3.91-3.74(\mathrm{~m}, 4 \mathrm{H}), 3.65$ (ddd, $J=12$, 5.6, $2 \mathrm{~Hz}, 1 \mathrm{H}), 2.39-2.38(\mathrm{~m}, 4 \mathrm{H}), 1.90-1.67(\mathrm{~m}, 17 \mathrm{H}), 1.34$ (br d, $J=12.4 \mathrm{~Hz}, 1 \mathrm{H}), 1.25$ (t, $J=$ $7.2 \mathrm{~Hz}, 3 \mathrm{H}), 0.90(\mathrm{~s}, 18 \mathrm{H}), 0.08(\mathrm{~s}, 3 \mathrm{H}), 0.07(\mathrm{~s}, 3 \mathrm{H}), 0.6(\mathrm{~s}, 3 \mathrm{H}), 0.04(\mathrm{~s}, 3 \mathrm{H}) ;{ }^{13} \mathrm{C}$ NMR $(100$ $\left.\mathrm{MHz}, \mathrm{CDCl}_{3}\right) \delta 172.7,133.2,128.4,119.3,119.2,81.3,81.1,78.5,72.2,69.4,67.6,64.9,60.3$, $37.2,37.1,36.2,35.9,33.6,28.9,27.6,26.1,25.8,23.9,23.5,23.3,23.3,18.3,18 ., 14.2,-4.3$, 4.4, -4.6, -4.8; IR (thin film) 2956, 1738, $1106 \mathrm{~cm}^{-1}$; HRMS (ESI) calcd for $\mathrm{C}_{38} \mathrm{H}_{68} \mathrm{O}_{9} \mathrm{Si}_{2} \mathrm{Na}$ $724.4402 \mathrm{~m} / \mathrm{z}(\mathrm{M}+\mathrm{Na})^{+}$; observed $747.4302 \mathrm{~m} / \mathrm{z}$.

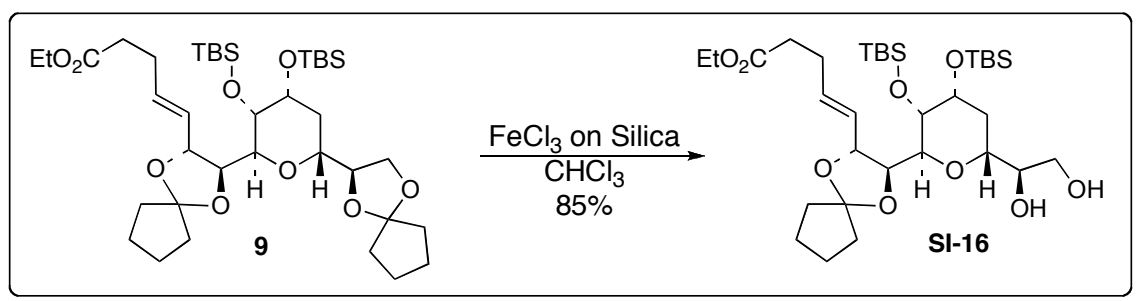

(E)-ethyl-5-((2R,3S)-3-((2S,3S,4R,6R)-3,4-bis(tert-butyldimethylsilyloxy)-6-((R)-1,2-

\section{dihydroxyethyl)tetrahydro-2H-pyran-2-yl)-1,4-dioxaspiro[4.4]nonan-2-yl)pent-4-enoate}

(SI-16). To a solution of bis-ketal $(260 \mathrm{mg}, 0.36 \mathrm{mmol})$ in $\mathrm{CHCl}_{3}(15 \mathrm{~mL})$ was added $\mathrm{FeCl}_{3}$ on $\mathrm{SiO}_{2}(75 \mathrm{mg})$. The reaction was monitored by TLC, judged complete after $3 \mathrm{~h}$, and then was filtered through a Celite plug. The resulting solution was concentrated in vacuo, and the resulting oil purified by column chromatography $(30 \%$ EtOAc-hexanes) to give the title 
compound as a clear oil $(135 \mathrm{mg}, 85 \%):[\alpha]_{\mathrm{D}}{ }^{25}=+7.74\left(c 1.0, \mathrm{CHCl}_{3}\right) ;{ }^{1} \mathrm{H} \mathrm{NMR}(400 \mathrm{MHz}$, $\left.\mathrm{CDCl}_{3}\right) \oint 5.88(\mathrm{dt}, J=15.2,6.4 \mathrm{~Hz}, 1 \mathrm{H}), 5.54(\mathrm{dd}, J=15.2,7.6 \mathrm{~Hz}, 1 \mathrm{H}), 4.20(\mathrm{t}, J=7.2 \mathrm{~Hz}, 1 \mathrm{H})$, 4.13 (q, $J=7.2 \mathrm{~Hz}, 2 \mathrm{H}), 4.02$ (ddd, $J=11.6,4,2.4 \mathrm{~Hz}, 1 \mathrm{H}), 3.96$ (br s, 1H), 3.81-3.74 (m, 2H), 3.69-3.64 (m, 2H), 3.61-3.50 (m, 2H), 2.69 (d, $J=5.6 \mathrm{~Hz}, 1 \mathrm{H}), 2.47-2.34(\mathrm{~m}, 4 \mathrm{H}), 2.33(\mathrm{t}, J=$ $6.4 \mathrm{~Hz}, 1 \mathrm{H}), 2.07(\mathrm{q}, J=12 \mathrm{~Hz}, 1 \mathrm{H}), 1.84-1.60(\mathrm{~m}, 8 \mathrm{H}), 1.42(\mathrm{dt}, J=11.6,3.2 \mathrm{~Hz}, 1 \mathrm{H}), 1.26(\mathrm{t}$, $J=7.2 \mathrm{~Hz}, 3 \mathrm{H}), 0.90(\mathrm{~s}, 18 \mathrm{H}), 0.09$ (s, 3H), 0.08 (s, 3H), 0.07 (s, 3H), $0.06(\mathrm{~s}, 3 \mathrm{H}) ;{ }^{13} \mathrm{C}$ NMR $\left(100 \mathrm{MHz}, \mathrm{CDCl}_{3}\right) \oint \underline{173.2,} 133.9,128.1,119.3,81.8,81.6,77.5,74.1,72.3,69.3,67.3,63.3$, $60.6,37.3,37.1,33.1,30.3,27.2,26.1,25.8,23.5,23.3,18.4,18.1,14.2,-4.3,-4.4,-4.6,-4.8$; IR (thin film) 3468, 2930, 1732, $835 \mathrm{~cm}^{-1}$; HRMS (ESI) calcd for $\mathrm{C}_{33} \mathrm{H}_{62} \mathrm{O}_{9} \mathrm{Si}_{2} \mathrm{Na} 681.3825 \mathrm{~m} / z$ $(\mathrm{M}+\mathrm{Na})^{+}$; observed $681.3810 \mathrm{~m} / \mathrm{z}$.

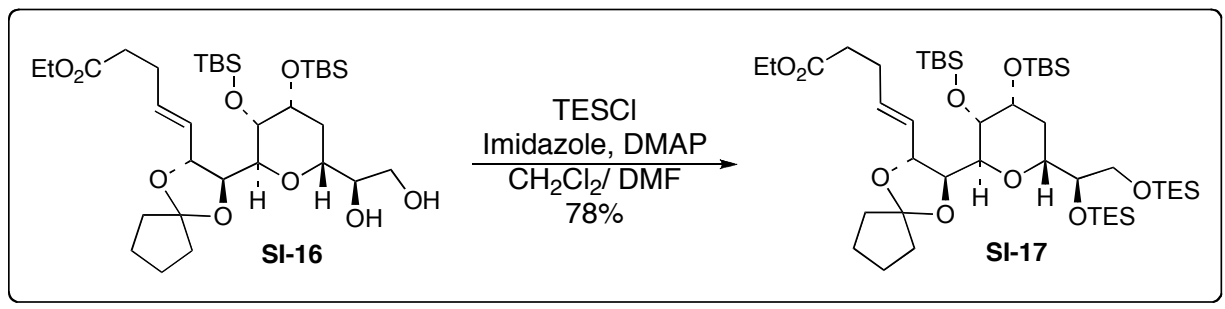

\section{(E)-ethyl-5-((2R,3S)-3-((2S,3S,4R,6R)-3,4-bis(tert-butyldimethylsilyloxy)-6-((R)-3,3,8,8-}

\section{tetraethyl-4,7-dioxa-3,8-disiladecan-5-yl)tetrahydro-2H-pyran-2-yl)-1,4-}

dioxaspiro[4.4]nonan-2-yl)pent-4-enoate (SI-17). To a solution of diol SI-16 (172 mg, 0.26 $\mathrm{mmol})$ in $\mathrm{CH}_{2} \mathrm{Cl}_{2}(2.5 \mathrm{~mL})$ and DMF $(2.5 \mathrm{~mL})$ cooled to $0{ }^{\circ} \mathrm{C}$ was added imidazole $(42 \mathrm{mg}, 0.62$ mmol), DMAP (3 mg, $0.02 \mathrm{mmol})$, and TESCl $(96 \mu 1,0.57 \mathrm{mmol})$. The reaction was allowed to warm to rt and stirred for 1h, then diluted with EtOAc:hexane (50:50) and quenched with sat. $\mathrm{NH}_{4} \mathrm{Cl}$. The aqueous phase was extrated with EtOAc:hexane (50:50) (x2) and the combine organics washed with brine, dried over $\mathrm{Na}_{2} \mathrm{SO}_{4}$, filtered and concentrated in vacuo. The resulting oil was purified by flash column chromatography ( $7 \%$ EtOAc-hexane) to give the title compound as a clear oil $(179 \mathrm{mg}, 78 \%):[\alpha]_{\mathrm{D}}{ }^{27}=+1.6\left(c 1.1, \mathrm{CHCl}_{3}\right) ;{ }^{1} \mathrm{H} \mathrm{NMR}(400 \mathrm{MHz}$, $\left.\mathrm{CDCl}_{3}\right) \oint 5.82$ (br d, $\left.J=15.6 \mathrm{~Hz}, 1 \mathrm{H}\right), 5.54(\mathrm{dd}, J=15.6,7.2 \mathrm{~Hz}, 1 \mathrm{H}), 4.16-4.10(\mathrm{~m}, 3 \mathrm{H}), 4.05$ (ddd, $J=11.6,4.4,2.7 \mathrm{~Hz}, 1 \mathrm{H}), 3.88$ (br s, $1 \mathrm{H}), 3.80-3.75(\mathrm{~m}, 2 \mathrm{H}), 3.71(\mathrm{dd}, J=6.8,1.2 \mathrm{~Hz}$, $1 \mathrm{H}), 3.62-3.59(\mathrm{~m}, 2 \mathrm{H}), 3.52(\mathrm{dd}, J=10,6.4 \mathrm{~Hz}, 1 \mathrm{H}), 2.38-2.37(\mathrm{~m}, 4 \mathrm{H}), 1.86-1.64(\mathrm{~m}, 9 \mathrm{H})$, 1.49 (br d, $J=11.6 \mathrm{~Hz}, 1 \mathrm{H}), 1.25$ (t, $J=7.2 \mathrm{~Hz}, 3 \mathrm{H}), 0.95$ (t, $J=8 \mathrm{~Hz}, 18 \mathrm{H}), 0.90$ (s, 9H), 0.88 $(\mathrm{s}, 9 \mathrm{H}), 0.64-0.54(\mathrm{~m}, 12 \mathrm{H}), 0.07(\mathrm{~s}, 3 \mathrm{H}), 0.06(\mathrm{~s}, 6 \mathrm{H}), 0.04(\mathrm{~s}, 3 \mathrm{H}) ;{ }^{13} \mathrm{C} \mathrm{NMR}(100 \mathrm{MHz}$, $\left.\mathrm{CDCl}_{3}\right) \oint 172.7,133.0,128.3,119.2,81.1,80.5,79.5,75.5,72.9,69.4,68.5,64.0,60.4,37.3$, 
37.2, 33.7, 29.2, 27.6, 26.1, 25.8, 23.4, 18.4, 18.1, 14.2, 6.9, 6.8, 5.0, 4.4, -4.3, -4.7, -4.8; IR (thin film) 2955, 1740, $1117 \mathrm{~cm}^{-1}$; HRMS (ESI) calcd for $\mathrm{C}_{45} \mathrm{H}_{90} \mathrm{O}_{9} \mathrm{Si}_{4} \mathrm{Na} 909.5554 \mathrm{~m} / z(\mathrm{M}+\mathrm{Na})^{+}$; observed $909.5558 \mathrm{~m} / z$; Anal calcd for $\mathrm{C}_{45} \mathrm{H}_{90} \mathrm{O}_{9} \mathrm{Si}_{4}: \mathrm{C}, 60.90 ; \mathrm{H}, 10.22$ Found: $\mathrm{C}, 61.30 ; \mathrm{H}$, 10.37 .

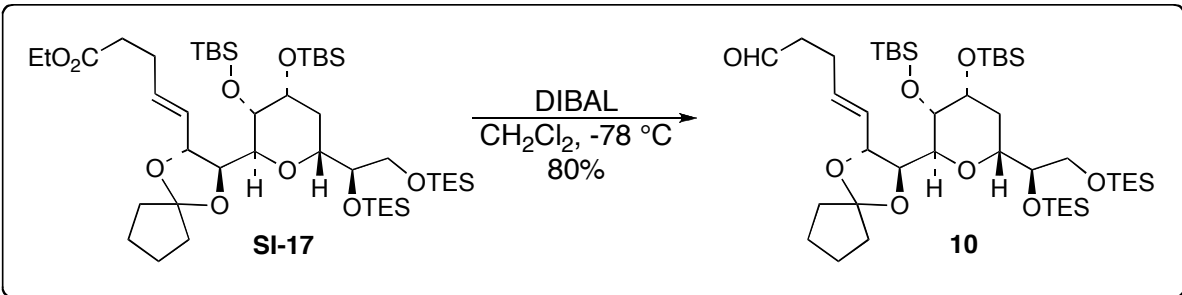

(E)-5-((2R,3S)-3-((2S,3S,4R,6R)-3,4-bis(tert-butyldimethylsilyloxy)-6-((R)-3,3,8,8-

tetraethyl-4,7-dioxa-3,8-disiladecan-5-yl)tetrahydro-2H-pyran-2-yl)-1,4-

dioxaspiro[4.4]nonan-2-yl)pent-4-enal (10). To a $-78{ }^{\circ} \mathrm{C}$ solution of ester SI-17 (179 mg, 0.20 $\mathrm{mmol})$ in $\mathrm{CH}_{2} \mathrm{Cl}_{2}(1.2 \mathrm{~mL})$ was added dropwise DIBAL (200 $\mu \mathrm{L}, 0.2 \mathrm{mmol}, 1 \mathrm{M}$ in toluene). The reaction was allowed to stir for $1 \mathrm{~h}$ at $-78^{\circ} \mathrm{C}$, then EtOAc $(100 \mu \mathrm{L})$ was added. The mixture was stirred an additional $10 \mathrm{~min}$, and then diluted with saturated sodium potassium tartrate solution and allowed to warm to ambient temperature and stirred overnight. The biphasic mixture was diluted with $\mathrm{CH}_{2} \mathrm{Cl}_{2}$, and the aqueous phase was extracted with $\mathrm{CH}_{2} \mathrm{Cl}_{2}(2 \mathrm{x})$. The combine organic extracts were washed with brine, dried over $\mathrm{Na}_{2} \mathrm{SO}_{4}$, filtered and concentrated in vacuo. The resulting oil was purified by flash column chromatography (5\% EtOAc-hexane) to give the title compound as a clear oil $(134 \mathrm{mg}, 80 \%):[\alpha]_{\mathrm{D}}{ }^{25}=+4.44\left(c 0.15, \mathrm{CHCl}_{3}\right) ;{ }^{1} \mathrm{H}$ NMR $(400$ $\left.\mathrm{MHz}, \mathrm{CDCl}_{3}\right) \oint 9.77(\mathrm{t}, J=1.2 \mathrm{~Hz}, 1 \mathrm{H}), 5.83(\mathrm{dt}, J=8.0,7.2 \mathrm{~Hz}, 1 \mathrm{H}), 5.59$ (dd, $J=6.8,2.4 \mathrm{~Hz}$, $1 \mathrm{H}), 4.15(\mathrm{t}, J=7.6 \mathrm{~Hz}, 1 \mathrm{H}), 4.04(\mathrm{ddd}, J=11.2,4.0,2.4 \mathrm{~Hz}, 1 \mathrm{H}), 3.89$ (br s, 1H), 3.80-3.45 (m, 2H), $3.71(\mathrm{dd}, J=6.8,1.6 \mathrm{~Hz}, 1 \mathrm{H}), 3.61-3.59$ (m, 2H), $3.52(\mathrm{dd}, J=10.0,6.0 \mathrm{~Hz}, 1 \mathrm{H}), 2.55(\mathrm{t}, J$ $=7.6 \mathrm{~Hz}, 2 \mathrm{H}), 2.38(\mathrm{q}, J=6.8 \mathrm{~Hz}, 2 \mathrm{H}), 1.86-1.65(\mathrm{~m}, 9 \mathrm{H}), 1.49(\mathrm{br} \mathrm{d}, J=11.6 \mathrm{~Hz}, 1 \mathrm{H}), 0.95(\mathrm{t}$, $J=8.0 \mathrm{~Hz}, 18 \mathrm{H}), 0.90(\mathrm{~s}, 9 \mathrm{H}), 0.89(\mathrm{~s}, 9 \mathrm{H}), 0.64-0.50(\mathrm{~m}, 12 \mathrm{H}), 0.07(\mathrm{~s}, 3 \mathrm{H}), 0.06(\mathrm{~s}, 3 \mathrm{H}), 0.05$ (s, 3H), 0.04 (s, 3H); ${ }^{13} \mathrm{C}$ NMR (100 MHz, $\left.\mathrm{CDCl}_{3}\right) \delta$ 201.3, 132.5, 128.6, 119.2, 81.1, 80.6, 79.4, 75.6, 72.9, 69.4, 68.5, 64.0, 43.0, 37.34, 37.25, 29.3, 26.1, 25.8, 24.8, 23.4, 18.4, 18.1, 6.9, 6.8, 5.0, 4.4, 1.0, -4.3, -4.6, -4.8; IR (thin film) 2954, 1731, $1118 \mathrm{~cm}^{-1}$; HRMS (ESI) calcd for $\mathrm{C}_{43} \mathrm{H}_{86} \mathrm{O}_{8} \mathrm{Si}_{4} \mathrm{Na} 865.5292 \mathrm{~m} / z(\mathrm{M}+\mathrm{Na})^{+}$; observed $865.5306 \mathrm{~m} / \mathrm{z}$; 


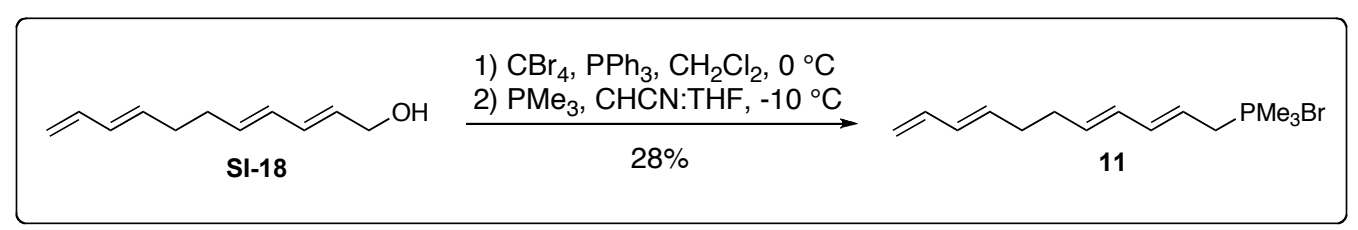

Trimethylphosphonium Salt (11). To a solution of $\mathrm{CBr}_{4}(2.01 \mathrm{~g}, 6.24 \mathrm{mmol})$ and $\mathrm{PPh}_{3}$ (2.2 $\mathrm{g}, 8.52 \mathrm{mmol})$ in $\mathrm{CH}_{2} \mathrm{Cl}_{2}(10 \mathrm{~mL})$ at $0{ }^{\circ} \mathrm{C}$ was added a solution of alcohol SI-18 ${ }^{1}(0.4 \mathrm{~g}, 2.43$ $\mathrm{mmol})$ in $\mathrm{CH}_{2} \mathrm{Cl}_{2}(2 \mathrm{~mL})$. The reaction was stirred for $10 \mathrm{~min}$, filtered through a $\mathrm{SiO}_{2}$ plug $(5 \%$ EtOAc-hexane), and the filtrate was concentrated in vacuo. The resulting dienylic bromide was dissolved in $\mathrm{CH}_{3} \mathrm{CN}(5 \mathrm{~mL})$ and sparged with Ar. Trimethylphosphine $(0.9 \mathrm{~mL}, 0.9 \mathrm{mmol}, 1 \mathrm{M}$ in THF) was added and the reaction was stirred $1 \mathrm{~h}$ are $\mathrm{rt}$. The resulting solution was concentrated in vacuo and placed under high vacuum overnight. The resulting oil was washed with pentane to give the title compound as an oil (210 mg, 28\%). ${ }^{1} \mathrm{H}$ NMR $\left(400 \mathrm{MHz}, \mathrm{CDCl}_{3}\right)$ $\oint 6.41$ (ddd, $J=15.6,10.4,5.6 \mathrm{~Hz}, 1 \mathrm{H}), 6.30$ (dt, $J=17.2,10 \mathrm{~Hz}, 1 \mathrm{H}), 6.10-6.00$ (m, 2H), 5.82$5.77(\mathrm{~m}, 1 \mathrm{H}), 5.67$ (dt, $J=15.6,8.4 \mathrm{~Hz}, 1 \mathrm{H}), 5.38$ (sextet, $J=8.8 \mathrm{~Hz}, 1 \mathrm{H}), 5.11$ (d, $J=16.8 \mathrm{~Hz}$, $1 \mathrm{H}), 4.98$ (d, $J=10 \mathrm{~Hz}, 1 \mathrm{H}), 3.54$ (dd, $J=16.4,8 \mathrm{~Hz}, 2 \mathrm{H}), 2.20-2.19$ (m, 4H), 2.17 (d, $J=14$ $\mathrm{Hz}, 9 \mathrm{H}) ;{ }^{13} \mathrm{C}$ NMR $\left(100 \mathrm{MHz}, \mathrm{CDCl}_{3}\right) \oint 139.3$ (d, $\left.J=13 \mathrm{~Hz}\right), 137.0,136.7$ (d, $\left.J=5 \mathrm{~Hz}\right), 133.9$, 131.6, $129.0(\mathrm{~d}, J=6 \mathrm{~Hz}), 115.3,114.7$ (d, $J=12 \mathrm{~Hz}) 32.2,31.9,27.9$ (d, $J=51 \mathrm{~Hz}), 8.5$ (d, $J=$ 54); IR (thin film) 3429, 2974, $965 \mathrm{~cm}^{-1}$; HRMS (ESI) calcd for $\mathrm{C}_{14} \mathrm{H}_{24} \mathrm{PNa} 223.1616 \mathrm{~m} / z$ $(\mathrm{M}+\mathrm{Na})^{+}$; observed $223.1605 \mathrm{~m} / \mathrm{z}$.

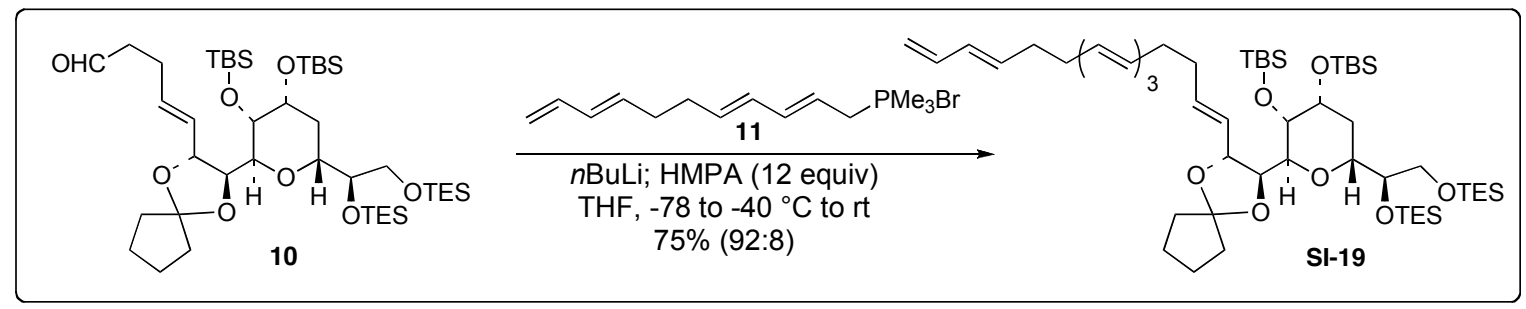

(R)-5-((2R,4R,5S,6S)-4,5-bis(tert-butyldimethylsilyloxy)-6-((2S,3R)-3-

((1E,5E,7E,9E,13E)-hexadeca-1,5,7,9,13,15-hexaenyl)-1,4-dioxaspiro[4.4]nonan-2-

yl)tetrahydro-2H-pyran-2-yl)-3,3,8,8-tetraethyl-4,7-dioxa-3,8-disiladecane (SI-19). To a suspension of trimethylphoshonium ylide $(54 \mathrm{mg}, 0.18 \mathrm{mmol})$ in $\mathrm{THF}(0.8 \mathrm{~mL})$ cooled to $-78{ }^{\circ} \mathrm{C}$ was added $n \mathrm{BuLi}$ (74 $\mu 1,0.17 \mathrm{mmol}, 2.3 \mathrm{M}$ in hexane) dropwise via syringe. The ylide solution was stirred at $-78{ }^{\circ} \mathrm{C}$ for $15 \mathrm{~min}$ and HMPA (375 $\left.\mu \mathrm{l}, 2.2 \mathrm{mmol}\right)$ was added. The mixture was stirred for $10 \mathrm{~min}$ at $-78{ }^{\circ} \mathrm{C}$, a solution of aldehyde $(51 \mathrm{mg}, 0.06 \mathrm{mmol})$ in THF $(0.8 \mathrm{~mL})$ was added dropwise. The reaction was stirred at $-78^{\circ} \mathrm{C}$ for $1 \mathrm{~h}$, warmed to $-40{ }^{\circ} \mathrm{C}$ for 40 min, then 
warmed to $\mathrm{rt}$ for $2 \mathrm{~h}$. The resulting soluion was diluted with $\mathrm{Et}_{2} \mathrm{O}$ and quenched with brine. The aqueous phase was extracted with $\mathrm{Et}_{2} \mathrm{O}(2 \mathrm{x})$ and the combine organic extracts were washed with brine, dried over $\mathrm{Na}_{2} \mathrm{SO}_{4}$, filtered and concentrated in vacuo. The resulting oil was purified by flash column chromatography (2\% EtOAc-hexane) to give the title compound as a clear oil (44 mg, 75\%): 6.30 (dt, $J=17.2,10.0 \mathrm{~Hz}, 1 \mathrm{H}), 6.09-6.02(\mathrm{~m}, 5 \mathrm{H}), 5.82$ (dt, $J=15.2,6.0 \mathrm{~Hz}, 1 \mathrm{H})$, 5.73-5.63 (m, 3H), 5.50 (dd, $J=15.2,7.2 \mathrm{~Hz}, 1 \mathrm{H}), 5.10(\mathrm{~d}, J=16.8 \mathrm{~Hz}, 1 \mathrm{H}), 4.97(\mathrm{~d}, J=10.0$ $\mathrm{Hz}, 1 \mathrm{H}), 4.16$ (t, $J=7.6 \mathrm{~Hz}, 1 \mathrm{H}), 4.06$ (ddd, $J=11.6,4.0,2.4 \mathrm{~Hz}, 1 \mathrm{H}), 3.89$ (s, 1H), 3.81-3.76 (m, 2H), $3.72(\mathrm{dd}, J=6.8,1.6 \mathrm{~Hz}, 1 \mathrm{H}), 3.62-3.60(\mathrm{~m}, 2 \mathrm{H}), 3.52$ (dd, $J=10.0,6.4 \mathrm{~Hz}, 1 \mathrm{H}), 2.19-$ $2.14(\mathrm{~m}, 8 \mathrm{H}), 1.87-1.63(\mathrm{~m}, 9 \mathrm{H}), 1.49$ (dd, $J=11.6,4.0 \mathrm{~Hz}, 1 \mathrm{H}), 0.96$ (t, $J=4.8 \mathrm{~Hz}, 18 \mathrm{H}), 0.90$ $(\mathrm{s}, 9 \mathrm{H}), 0.89(\mathrm{~s}, 9 \mathrm{H}), 0.64-0.54(\mathrm{~m}, 12 \mathrm{H}), 0.07(\mathrm{~s}, 3 \mathrm{H}), 0.06(\mathrm{~s}, 6 \mathrm{H}), 0.04(\mathrm{~s}, 3 \mathrm{H})$.

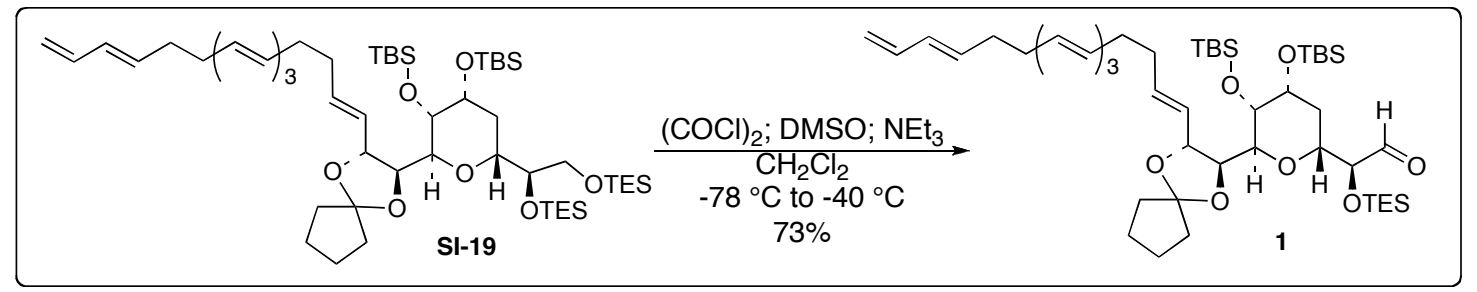

$(R)-3,3,8,8$-tetraethyl-5-((2R,4R,5R,6R)-6-((4S,5R)-5-((1E,5E,7E,9E,13E)-hexadeca-

\section{1,5,7,9,13,15-hexaenyl)-2,2-dimethyl-1,3-dioxolan-4-yl)-4,5-bis(4-}

methoxybenzyloxy)tetrahydro-2H-pyran-2-yl)-4,7-dioxa-3,8-disiladecane (1). To a $-78{ }^{\circ} \mathrm{C}$ solution of distilled oxalyl chloride $(10.5 \mu \mathrm{L}, 0.12 \mathrm{mmol})$ in $\mathrm{CH}_{2} \mathrm{Cl}_{2}(0.2 \mathrm{~mL})$ was added dropwise a solution of dimethyl sulfoxide $(15 \mu \mathrm{L}, 0.21 \mathrm{mmol})$ in $\mathrm{CH}_{2} \mathrm{Cl}_{2}(0.2 \mathrm{~mL})$. The resulting solution was stirred for $5 \mathrm{~min}$ at $-78{ }^{\circ} \mathrm{C}$. A solution of TES-ether SI-19 (24 mg, 0.024 $\mathrm{mmol})$ in $\mathrm{CH}_{2} \mathrm{Cl}_{2}(0.5 \mathrm{~mL})$ was added and the reaction mixture was allowed to stir $20 \mathrm{~min}$ at -78 ${ }^{\circ} \mathrm{C}$. The reaction was warmed to $-40{ }^{\circ} \mathrm{C}$ for $20 \mathrm{~min}$, then cooled to $-78{ }^{\circ} \mathrm{C}$. Triethylamine $(0.8$ $\mathrm{mL}, 5.7 \mathrm{mmol}$ ) was added, the reaction was warmed to ambient temperature. The reaction mixture was concentrated in vacuo and the resulting white solid was suspended in $\mathrm{Et}_{2} \mathrm{O}$, filtered though Celite, and concentrated in vacuo to give a yellow oil $(15 \mathrm{mg}, 73 \%):[\alpha]_{\mathrm{D}}{ }^{27}=+17.2(c$ 0.18, $\mathrm{CHCl}_{3}$ ); ${ }^{1} \mathrm{H} \mathrm{NMR}\left(400 \mathrm{MHz}, \mathrm{CDCl}_{3}\right) \oint 9.63$ (s, 1H), 6.23 (dt, $\left.J=17.2,10 \mathrm{~Hz}, 1 \mathrm{H}\right), 6.02-$ $5.96(\mathrm{~m}, 5 \mathrm{H}), 5.76(\mathrm{dt}, J=15.2,6 \mathrm{~Hz}, 1 \mathrm{H}), 5.66-5.57(\mathrm{~m}, 3 \mathrm{H}), 5.40(\mathrm{dd}, J=15.2,7.2 \mathrm{~Hz}, 1 \mathrm{H})$, $5.03(J=16.8 \mathrm{~Hz}, 1 \mathrm{H}), 4.90(\mathrm{~d}, J=10 \mathrm{~Hz}, 1 \mathrm{H}), 4.08-4.00(\mathrm{~m}, 2 \mathrm{H}), 3.85-3.82(\mathrm{~m}, 3 \mathrm{H}), 3.71-$ $3.68(\mathrm{~m}, 2 \mathrm{H}), 2.12-2.11(\mathrm{~m}, 8 \mathrm{H}), 2.01(\mathrm{q}, J=12 \mathrm{~Hz}, 1 \mathrm{H}), 1.74-1.55(\mathrm{~m}, 8 \mathrm{H}), 1.37$ (br d, $J=10.8$ $\mathrm{Hz}, 1 \mathrm{H}), 0.89$ (t, $J=8 \mathrm{~Hz}, 9 \mathrm{H}), 0.83$ (s, 9H), 0.82 (s, 9H), 0.57 (q, $9.6 \mathrm{~Hz}, 6 \mathrm{H}), 0.00$ (s, 6H), $0.01(\mathrm{~s}, 3 \mathrm{H}),-0.3(\mathrm{~s}, 3 \mathrm{H}) ;{ }^{13} \mathrm{C} \mathrm{NMR}\left(100 \mathrm{MHz}, \mathrm{CDCl}_{3}\right) \oint 203.6,137.4,135.6,134.6,133.7$, 
$133.5,131.6,131.4,131.2,131.2,127.5,119.5,115.3,81.7,81.2,73.8,69.4,68.2,37.62,37.55$, 32.7, 32.6, 32.4, 32.3, 30.3, 26.4, 26.1, 23.7, 23.6, 18.6, 18.4, 7.0, 5.0, -4.0, -4.1, -4.4, -4.5; IR (thin film) 2929, 1737, $1114 \mathrm{~cm}^{-1}$; HRMS (ESI) calcd for $\mathrm{C}_{48} \mathrm{H}_{84} \mathrm{O}_{7} \mathrm{Si}_{3} \mathrm{Na} 879.5423 \mathrm{~m} / z$ $(\mathrm{M}+\mathrm{Na})^{+}$; observed $879.5405 \mathrm{~m} / \mathrm{z}$.

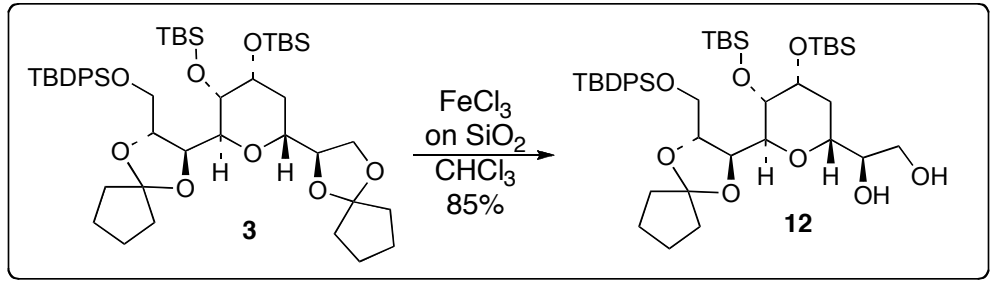

(R)-1-((2R,4R,5S,6S)-4,5-bis(tert-butyldimethylsilyloxy)-6-((2S,3R)-3-((tert-

butyldiphenylsilyloxy)methyl)-1,4-dioxaspiro[4.4]nonan-2-yl)tetrahydro-2H-pyran-2-

yl)ethane-1,2-diol (12). To a solution of bis-ketal $(10.8 \mathrm{mg}, 0.013 \mathrm{mmol})$ in $\mathrm{CHCl}_{3}(1 \mathrm{~mL})$ was added $\mathrm{FeCl}_{3}$ on $\mathrm{SiO}_{2}(5 \mathrm{mg})$. The reaction was monitored by TLC, judged complete after $2 \mathrm{~h}$, and then was filtered through a glass wool plug. The solution was concentrated in vacuo, and the resulting oil purified by column chromatography (20\% EtOAc-hexanes to 50\% EtOAc-hexanes) to give the title compound as a clear oil $(8.9 \mathrm{mg}, 85 \%):[\alpha]_{\mathrm{D}}{ }^{25}=+1.9\left(c 0.65, \mathrm{CHCl}_{3}\right) ;{ }^{1} \mathrm{H} \mathrm{NMR}$ $\left(400 \mathrm{MHz}, \mathrm{CDCl}_{3}\right) \oint 7.71-7.69(\mathrm{~m}, 4 \mathrm{H}), 7.46-7.37$ (m, 6H), $4.22(\mathrm{dd}, J=9.6,6.8 \mathrm{~Hz}, 1 \mathrm{H}), 4.07$ $(\mathrm{ddd}, J=11.6,4,2.4 \mathrm{~Hz}, 1 \mathrm{H}), 4.00-3.96(\mathrm{~m}, 2 \mathrm{H}), 3.92(\mathrm{dd}, J=11.2,2.8 \mathrm{~Hz}, 1 \mathrm{H}), 3.76(\mathrm{dd}, J=$ 9.6, 1.6 Hz, 1H), 3.71 (dd, $J=11.2,4.4 \mathrm{~Hz}, 1 \mathrm{H}), 3.59$ (br d, $J=12 \mathrm{~Hz}, 1 \mathrm{H}), 3.41-3.40$ (m, 3H), $2.39(\mathrm{~d}, J=6 \mathrm{~Hz}, 1 \mathrm{H}), 2.12(\mathrm{q}, J=12 \mathrm{~Hz}, 1 \mathrm{H}), 1.86-1.65(\mathrm{~m}, 9 \mathrm{H}), 1.35(\mathrm{dt}, J=12.4,3.6 \mathrm{~Hz}$, 1H), 1.07 (s, 9H), $0.91(\mathrm{~s}, 9 \mathrm{H}), 0.90(\mathrm{~s}, 9 \mathrm{H}), 0.09$ (s, 3H), 0.08 (s, 3H), 0.07 (s, 3H), 0.06 (s, 3H); ${ }^{13} \mathrm{C}$ NMR $\left(100 \mathrm{MHz}, \mathrm{CDCl}_{3}\right) \oint 135.8,135.7,133.3,133.1,129.9,129.8,127.8,127.7,119.5$, $81.8,81.5,77.2,73.9,73.0,72.2,69.4,67.2,63.6,63.5,37.6,37.3,30.4,29.7,26.8,26.2,25.8$, 23.4, 23.3, 19.3, 18.4, 18.1, -4.3, -4.4, -4.7, -4.8; IR (thin film) 2929, 2857, $1113 \mathrm{~cm}^{-1}$; HRMS (ESI) calcd for $\mathrm{C}_{43} \mathrm{H}_{72} \mathrm{O}_{8} \mathrm{Si}_{3} \mathrm{Na} 823.4433 \mathrm{~m} / z(\mathrm{M}+\mathrm{Na})^{+}$; observed $823.4462 \mathrm{~m} / \mathrm{z}$.

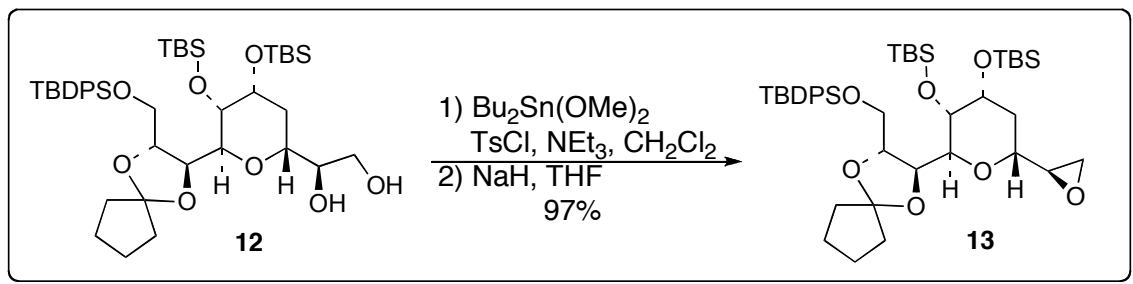

((2S,3S,4R,6R)-2-((2S,3R)-3-((tert-butyldiphenylsilyloxy)methyl)-1,4dioxaspiro[4.4]nonan-2-yl)-6-((R)-oxiran-2-yl)tetrahydro-2H-pyran-3,4- 
diyl)bis(oxy)bis(tert-butyldimethylsilane) (13). To a solution of diol (1.60g, $1.99 \mathrm{mmol})$ in $\mathrm{CH}_{2} \mathrm{Cl}_{2}(6 \mathrm{~mL})$ was added $\mathrm{NEt}_{3}(280 \mu \mathrm{L}, 1.99 \mathrm{mmol})$, TsCl $(379 \mathrm{mg}, 1.99 \mathrm{mmol})$, and $\mathrm{Bu}_{2} \mathrm{Sn}(\mathrm{OMe})_{2}(11 \mu \mathrm{L}, 0.04 \mathrm{mmol}){ }^{5}$ After $2 \mathrm{~h}$, the reaction mixture was diluted with $\mathrm{CH}_{2} \mathrm{Cl}_{2}$ and $\mathrm{H}_{2} \mathrm{O}$, the aqueous layer was extracted with $\mathrm{CH}_{2} \mathrm{Cl}_{2}(\mathrm{x} 2)$ and the combine organics were washed with brine; dried over $\mathrm{Na}_{2} \mathrm{SO}_{4}$, filtered and concentrated. The resulting tosylate was dissolved in THF, cooled to $0{ }^{\circ} \mathrm{C}$, and $\mathrm{NaH}(103 \mathrm{mg}, 12.58 \mathrm{mmol}, 60 \%$ dispersion in oil) was added. The reaction was allowed to warm to $\mathrm{rt}$ and stir overnight. An additional aliquot of $\mathrm{NaH}(100 \mathrm{mg}, 2.5$ mmol) was added. Upon completion the reaction mixture was quenched with sat. $\mathrm{NaHCO}_{3}$ and diluted with EtOAc. The aqueous phase was extracted with EtOAc and the combine extracts were washed with brine; dried over $\mathrm{Na}_{2} \mathrm{SO}_{4}$, filtered, and concentrated. The resulting oil was purified by column chromatography (30\% EtOAc-hexane) to give the title compound (1.56 g, 97\%): $[\alpha]_{\mathrm{D}}{ }^{27}=+17.6\left(c\right.$ 1.9, $\left.\mathrm{CHCl}_{3}\right) ;{ }^{1} \mathrm{H}$ NMR (400 MHz, $\left.\mathrm{CDCl}_{3}\right) \oint 7.66(\mathrm{dd}, J=7.6,1.2 \mathrm{~Hz}$, 2H), 7.62 (dd, $J=7.6,1.6 \mathrm{~Hz}, 2 \mathrm{H}), 7.34-7.27$ (m, 6H), 4.28 (dd, $J=9.6,6.8 \mathrm{~Hz}, 1 \mathrm{H}), 3.99$ (ddd, $J=10.4,5.2,3.2 \mathrm{~Hz}, 1 \mathrm{H}), 3.94$ (br s, $1 \mathrm{H}), 3.92-3.88(\mathrm{~m}, 2 \mathrm{H}), 3.80$ (dd, $J=11.6,3.2 \mathrm{~Hz}, 1 \mathrm{H})$, $3.71(\mathrm{dd}, J=10,1.6 \mathrm{~Hz}, 1 \mathrm{H}), 3.26(\mathrm{ddd}, J=12.0,6.4,2.4 \mathrm{~Hz}, 1 \mathrm{H}), 2,85(\mathrm{ddd}, J=6.4,3.6,2.4$ Hz, 1H), 2.60 (t, $J=4.8 \mathrm{~Hz}, 1 \mathrm{H}), 2.26$ (dd, $J=5.2,2.8 \mathrm{~Hz}, 1 \mathrm{H}), 1.97$ (q, $J=12 \mathrm{~Hz}, 1 \mathrm{H}), 1.80-$ $1.56(\mathrm{~m}, 8 \mathrm{H}), 1.30$ (br d, $J=12 \mathrm{~Hz}, 1 \mathrm{H}), 0.96(\mathrm{~s}, 9 \mathrm{H}), 0.83(\mathrm{~s}, 18 \mathrm{H}), 0.02$ (s, 3H), $0.01(\mathrm{~s}, 3 \mathrm{H})$, $0.00(\mathrm{~s}, 3 \mathrm{H}), 0.01(\mathrm{~s}, 3 \mathrm{H}) ;{ }^{13} \mathrm{C} \mathrm{NMR}\left(125 \mathrm{MHz}, \mathrm{CDCl}_{3}\right) \delta 135.9,135.7,133.7,133.2,129.7$, 127.7, 127.6, 119.1, 82.0, 81.5, 73.9, 72.0, 69.6, 67.5, 63.0, 54.1, 43.6, 37.4, 37.2, 30.8, 26.9, 26.2, 25.9, 23.5, 23.2, 19.4, 18.5, 18.2, -4.3, -4.7, -4.7; IR (thin film) 2930, 1472, $1114 \mathrm{~cm}^{-1}$; HRMS (ESI) calcd for $\mathrm{C}_{43} \mathrm{H}_{70} \mathrm{O}_{7} \mathrm{Si}_{3} \mathrm{Na} 805.4327 \mathrm{~m} / z(\mathrm{M}+\mathrm{Na})^{+}$; observed $805.4329 \mathrm{~m} / z$.

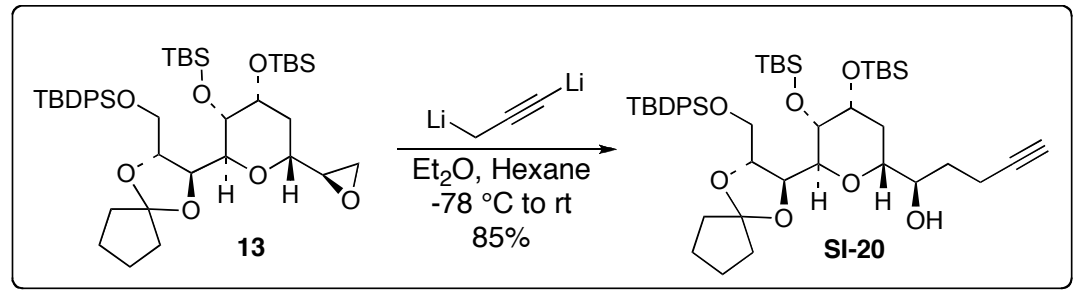

\section{(R)-1-((2R,4R,5S,6S)-4,5-bis(tert-butyldimethylsilyloxy)-6-((2S,3R)-3-((tert-} butyldiphenylsilyloxy)methyl)-1,4-dioxaspiro[4.4]nonan-2-yl)tetrahydro-2H-pyran-2-

yl)pent-4-yn-1-ol (SI-20). To a solution of epoxide (1.55 g, $1.98 \mathrm{mmol})$ in THF (2 mL) cooled to $-78^{\circ} \mathrm{C}$, was added a solution of dilithopropyne ${ }^{6}(124 \mathrm{~mL}, 0.5 \mathrm{M}$ in hexane, $\sim 62 \mathrm{mmol})$. The reaction was stirred $1 \mathrm{~h}$ at $-78{ }^{\circ} \mathrm{C}$, then quenched with sat. $\mathrm{NH}_{4} \mathrm{Cl}$, diluted with EtOAc. The 
aqueous phase was extracted with EtOAc (x2)and the combine organics were washed with brine. The extracts were dried over $\mathrm{Na}_{2} \mathrm{SO}_{4}$, filtered, and concentrated in vácuo. The resulting oil was purified by column chromatography (10\% EtOAc-hexane) to give the title compound (1.38 $\mathrm{mg}$, 85\%): $[\alpha]_{\mathrm{D}}{ }^{27}=+13.7\left(c\right.$ 5.6, $\left.\mathrm{CHCl}_{3}\right) ;{ }^{1} \mathrm{H}$ NMR (400 MHz, $\mathrm{CDCl}_{3}$ ) $\oint 7.73-7.67$ (m, 4H), 7.46$7.37(\mathrm{~m}, 6 \mathrm{H}), 4.27(\mathrm{dd}, J=9.6,6.8 \mathrm{~Hz}, 1 \mathrm{H}), 4.08(\mathrm{ddd}, J=11.6,4.0,2.5 \mathrm{~Hz}, 1 \mathrm{H}), 4.00-3.91(\mathrm{~m}$, $3 \mathrm{H}), 3.77-3.71(\mathrm{~m}, 2 \mathrm{H}), 3.45-3.30(\mathrm{~m}, 2 \mathrm{H}), 2.30-2.25(\mathrm{~m}, 2 \mathrm{H}), 2.19(\mathrm{~d}, J=5.6 \mathrm{~Hz}, 1 \mathrm{H}), 2.07$ (q, $J=12 \mathrm{~Hz}, 1 \mathrm{H}), 1.94(\mathrm{t}, J=2.4 \mathrm{~Hz}, 1 \mathrm{H}), 1.87-1.67(\mathrm{~m}, 8 \mathrm{H}), 1.52-1.48(\mathrm{~m}, 1 \mathrm{H}), 1.41-1.35(\mathrm{~m}$, 2H), 1.07 (s, 9H), $0.92(\mathrm{~s}, 9 \mathrm{H}), 0.90(\mathrm{~s}, 9 \mathrm{H}), 0.09(\mathrm{~s}, 6 \mathrm{H}), 0.08(\mathrm{~s}, 3 \mathrm{H}), 0.06(\mathrm{~s}, 3 \mathrm{H}) ;{ }^{13} \mathrm{C}$ NMR $\left(125 \mathrm{MHz}, \mathrm{CDCl}_{3}\right) \delta 135.8,135.7,133.3,133.1,129.9,129.8,127.8,127.7,119.4,84.2,81.8$, $81.4,74.5,73.0,72.6,69.5,68.5,67.4,63.4,37.6,37.3,31.8,30.8,37.6,26.2,25.9,23.5,23.3$, 19.3, 18.5, 18.2, 14.9, -4.30, -4.33, -4.67, -4.7; IR (thin film) 3565, 3313, 2930, $1114 \mathrm{~cm}^{-1}$; HRMS (ESI) calcd for $\mathrm{C}_{46} \mathrm{H}_{74} \mathrm{O}_{7} \mathrm{Si}_{3} \mathrm{Na} 845.4640 \mathrm{~m} / z(\mathrm{M}+\mathrm{Na})^{+}$; observed $845.4626 \mathrm{~m} / z$.

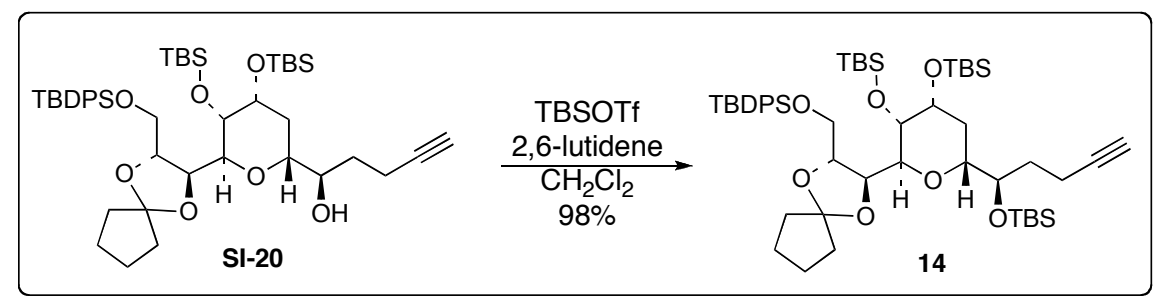

$((2 S, 3 S, 4 R, 6 R)-6-((R)-1-($ tert-butyldimethylsilyloxy)pent-4-ynyl)-2-((2S,3R)-3-((tertbutyldiphenylsilyloxy)methyl)-1,4-dioxaspiro[4.4]nonan-2-yl)tetrahydro-2H-pyran-3,4diyl)bis(oxy)bis(tert-butyldimethylsilane) (14). To a solution of alcohol (1.38 g, $1.67 \mathrm{mmol})$ in $\mathrm{CH}_{2} \mathrm{Cl}_{2}$ at $-40{ }^{\circ} \mathrm{C}(9 \mathrm{~mL})$ was added 2,6 -lutidine $(257 \mu \mathrm{l}, 2.34 \mathrm{mmol})$ and TBSOTf $(421 \mu \mathrm{l}, 1.83$ mmol). The reaction was stirred $10 \mathrm{~min}$ at $-40{ }^{\circ} \mathrm{C}$ then warmed to $\mathrm{rt}$ and judged incomplete by TLC analysis. A second equivalent of 2,6-lutidine $(257 \mu \mathrm{l}, 2.34 \mathrm{mmol})$ and TBSOTf (421 $\mu 1$, $1.83 \mathrm{mmol}$ ) was added. Upon completion the reaction mixture was quenched with sat. $\mathrm{NaHCO}_{3}$ and diluted with $\mathrm{CH}_{2} \mathrm{Cl}_{2}$. The aqueous phase was extracted with $\mathrm{CH}_{2} \mathrm{Cl}_{2}$ and the combine extracts were washed with brine; dried over $\mathrm{Na}_{2} \mathrm{SO}_{4}$, filtered, and concentrated. The resulting oil was purified by column chromatography (5\% EtOAc-hexane) to give the title compound (1.54 g, 98\%): $[\alpha]_{\mathrm{D}}{ }^{27}=+20.8\left(c\right.$ 3.2, $\left.\mathrm{CHCl}_{3}\right) ;{ }^{1} \mathrm{H} \mathrm{NMR}\left(400 \mathrm{MHz}, \mathrm{CDCl}_{3}\right) \oint 7.73-7.68(\mathrm{~m}, 4 \mathrm{H}), 7.44$ $7.34(\mathrm{~m}, 6 \mathrm{H}), 4.10(\mathrm{t}, J=7.6 \mathrm{~Hz}, 1 \mathrm{H}), 4.06(\mathrm{ddd}, J=11.6,6.8,2.4 \mathrm{~Hz}, 1 \mathrm{H}), 3.98-3.94(\mathrm{~m}, 2 \mathrm{H})$, $3.89(\mathrm{dd}, J=11.2,2.4 \mathrm{~Hz}, 1 \mathrm{H}), 3.77(\mathrm{dd}, J=11.2,5.2 \mathrm{~Hz}, 1 \mathrm{H}), 3.71(\mathrm{dd}, J=8,1.2 \mathrm{~Hz}, 1 \mathrm{H}), 3.63$ $(\mathrm{ddd}, J=8.8,5.6,3.2 \mathrm{~Hz}, 1 \mathrm{H}), 3.52(\mathrm{ddd}, J=11.6,5.2,2 \mathrm{~Hz}, 1 \mathrm{H}), 2.26-2.17(\mathrm{~m}, 2 \mathrm{H}), 1.91(\mathrm{t}, J$ 
$=2.8 \mathrm{~Hz}, 1 \mathrm{H}), 1.76(\mathrm{q}, J=12 \mathrm{~Hz}, 1 \mathrm{H}), 1.81-1.54(\mathrm{~m}, 10 \mathrm{H}), 1.45(\mathrm{br} \mathrm{d}, J=11.6 \mathrm{~Hz}, 1 \mathrm{H}), 1.06$ (s, 9H), 0.90 (s, 9H), 0.89 (s, 9H), 0.82 (s, 9H), 0.09 (s, 3H), 0.08 (s, 3H), 0.07 (s, 3H), 0.06 (s, $3 \mathrm{H}), 0.00(\mathrm{~s}, 3 \mathrm{H}),-0.01$ (s, 3H); ${ }^{13} \mathrm{C}$ NMR $\left(125 \mathrm{MHz}, \mathrm{CDCl}_{3}\right) \delta 135.8,135.7,133.5,133.4$, $129.69,129.65,127.7,127.6,119.3,84.6,81.4,74.4,74.1,72.9,69.5,68.4,68.2,64.0,37.4$, $37.0,30.8,28.9,26.926 .2,25.9,25.8,23.4,23.2,19.3,18.5,18.2,18.1,14.8,-4.2,-4.27,-4.33$, 4.6, -4.8, -4.9; IR (thin film) 3314, 2956, $1114 \mathrm{~cm}^{-1}$; HRMS (ESI) calcd for $\mathrm{C}_{52} \mathrm{H}_{88} \mathrm{O}_{7} \mathrm{Si}_{4}$ $959.5505 \mathrm{~m} / z(\mathrm{M}+\mathrm{Na})^{+}$; observed $959.5517 \mathrm{~m} / \mathrm{z}$.

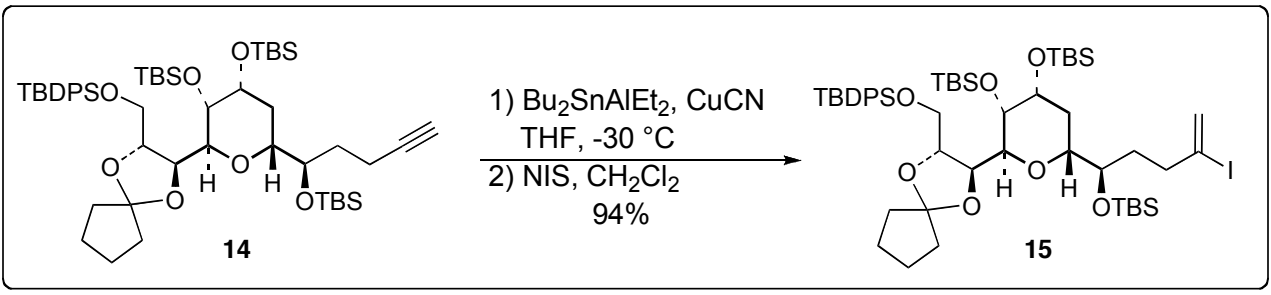

((2S,3S,4R,6R)-6-((R)-1-(tert-butyldimethylsilyloxy)-4-iodopent-4-enyl)-2-((2S,3R)-3((tert-butyldiphenylsilyloxy)methyl)-1,4-dioxaspiro[4.4]nonan-2-yl)tetrahydro-2H-pyran-

3,4-diyl)bis(oxy)bis(tert-butyldimethylsilane) (15). To a solution of diisopropylamine (3.8 $\mathrm{mL}$, $27.0 \mathrm{mmol})$ in THF $(24 \mathrm{~mL})$ cooled to $0{ }^{\circ} \mathrm{C}$ was added with $n$-BuLi $(10 \mathrm{~mL}, 2.4 \mathrm{M}$ in hexane, $24.0 \mathrm{mmol})$. The solution was stirred $30 \mathrm{~min}$ at $0{ }^{\circ} \mathrm{C}$, cooled to $-30{ }^{\circ} \mathrm{C}$, and $n-\mathrm{Bu}_{3} \mathrm{SnH}(6.8 \mathrm{~mL}$, $24.0 \mathrm{mmol})$ in THF $(40 \mathrm{~mL})$ was added. After stirring $1 \mathrm{~h}$, a solution of $\mathrm{Et}_{2} \mathrm{AlCl}(13.2 \mathrm{~mL}, 1.8 \mathrm{M}$ in toluene, $20 \mathrm{mmol}$ ) was added and the reaction was stirred $5 \mathrm{~h}$ at $-30{ }^{\circ} \mathrm{C}$ to generate the desired stannylalumination reagent. ${ }^{7}$

To a solution of alkyne $(780 \mathrm{mg}, 0.83 \mathrm{mmol})$ in THF $(31 \mathrm{~mL})$ cooled to $-30{ }^{\circ} \mathrm{C}$, was added $\mathrm{Bu}_{3} \mathrm{SnAlEt}_{2}$ (17 $\mathrm{mL}$ of above solution, $4.1 \mathrm{mmol}$ ) and $\mathrm{CuCN}$ (22 mg, $0.25 \mathrm{mmol}$ ). Upon completion by TLC analysis (2h), the reaction was quenched with $\mathrm{NH}_{4} \mathrm{Cl}$ and stirred 20 min. The reaction was diluted with EtOAc and, the resulting aqueaus phase extracted with EtOAc (x2). The combine organics were washed with brine, dried over $\mathrm{Na}_{2} \mathrm{SO}_{4}$, filtered, and concentrated. The resulting oil was purified by column chromatography (hexane to 5\% EtOAchexane) to give the vinyl stannane.

To a solution of vinyl stannane in $\mathrm{CH}_{2} \mathrm{Cl}_{2}(20 \mathrm{~mL})$ was added NIS (342 mg, $\left.1.52 \mathrm{mmol}\right)$. The reaction was stirred 10 min, then filtered though and $\mathrm{SiO}_{2}$ plug eluted with $\mathrm{CH}_{2} \mathrm{Cl}_{2}: \mathrm{Et}_{2} \mathrm{O}$. The resulting oil was purified by column chromatography (5\% EtOAc-hexane) to give the title compound (834 mg, 94\%). $[\alpha]_{\mathrm{D}}{ }^{27}=+18.2\left(c 2.6, \mathrm{CHCl}_{3}\right) ;{ }^{1} \mathrm{H} \mathrm{NMR}\left(400 \mathrm{MHz}, \mathrm{CDCl}_{3}\right) \delta 7.73-$ $7.68(\mathrm{~m}, 4 \mathrm{H}), 7.44-7.35(\mathrm{~m}, 6 \mathrm{H}), 5.97(\mathrm{~d}, J=1.2 \mathrm{~Hz}, 1 \mathrm{H}), 5.66(\mathrm{~d}, J=1.2 \mathrm{~Hz}, 1 \mathrm{H}), 4.14(\mathrm{t}, J=$ 
$8.0 \mathrm{~Hz}, 1 \mathrm{H}), 4.06$ (ddd, $J=10.8,6.4,4 \mathrm{~Hz}, 1 \mathrm{H}), 4.00-3.96(\mathrm{~m}, 2 \mathrm{H}), 3.49$ (dd, $J=11.2,2.8 \mathrm{~Hz}$, $1 \mathrm{H}), 3.79(\mathrm{dd}, J=11.2,4.8 \mathrm{~Hz}, 1 \mathrm{H}), 3.72(\mathrm{dd}, J=8.4,1.2 \mathrm{~Hz}, 1 \mathrm{H}), 3.51-3.48(\mathrm{~m}, 2 \mathrm{H}), 2.46-$ 2.37 (m, 2H), 1.87 (q, $J=12 \mathrm{~Hz}, 1 \mathrm{H}), 1.83-1.54(\mathrm{~m}, 10 \mathrm{H}), 1.45$ (br d, $J=10 \mathrm{~Hz}, 1 \mathrm{H}), 1.06$ (s, 9H), 0.91 (s, 9H), 0.90 (s, 9H), $0.82(\mathrm{~s}, 9 \mathrm{H}), 0.08$ (s, 3H), $0.072(\mathrm{~s}, 3 \mathrm{H}), 0.068$ (s, 3H), 0.04 (s, $3 \mathrm{H}),-0.03(\mathrm{~s}, 3 \mathrm{H}),-0.11(\mathrm{~s}, 3 \mathrm{H}) ;{ }^{13} \mathrm{C} \mathrm{NMR}\left(125 \mathrm{MHz}, \mathrm{CDCl}_{3}\right) \delta 135.8,135.7,133.5,133.4$, $129.69,129.66,127.7,127.6,124.9,119.3,112.3,81.5,81.4,74.1,74.2,69.5,68.1,64.0,41.8$, 37.4, 36.9, 32.1, 28.9, 26.9, 26.2, 25.90, 23.4, 23.2, 19.3, 18.5, 18.2, 18.1, -4.3, -4.4, -4.6, -4.81, 4.83; IR (thin film) 3050, 2930, $1113 \mathrm{~cm}^{-1}$; HRMS (ESI) calcd for $\mathrm{C}_{52} \mathrm{H}_{89} \mathrm{IO}_{7} \mathrm{Si}_{4} 1087.4628 \mathrm{~m} / z$ $(\mathrm{M}+\mathrm{Na})^{+}$; observed $1087.4629 \mathrm{~m} / z$.

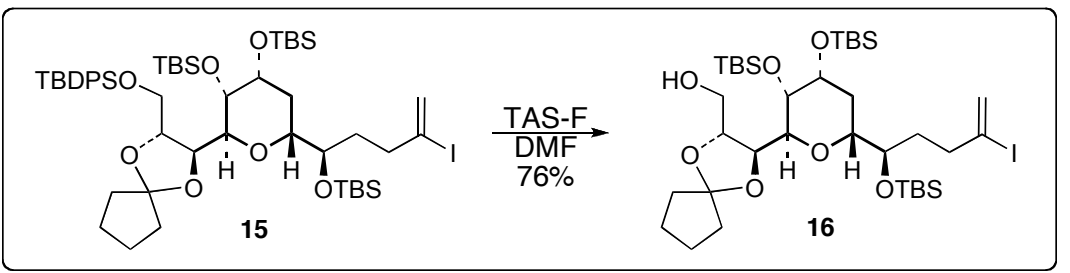

$((2 R, 3 S)-3-((2 S, 3 S, 4 R, 6 R)-3,4-b i s($ tert-butyldimethylsilyloxy)-6-((R)-1-(tert-

butyldimethylsilyloxy)-4-iodopent-4-enyl)tetrahydro-2H-pyran-2-yl)-1,4-

dioxaspiro[4.4]nonan-2-yl)methanol (16). To a solution of silyl ether (727 $\mathrm{mg}, 0.78 \mathrm{mmol})$ in DMF $(4.3 \mathrm{~mL})$ was added a solution of TAS-F $(268 \mathrm{mg}, 0.97 \mathrm{mmol}, 0.4 \mathrm{M}$ in DMF). The reaction was judged complete after $2 \mathrm{~h}$ and diluted with EtOAc and $\mathrm{pH} 7$ buffer. The aqueous phase was extracted with EtOAc (x2) and the combined extracts were washed with brine. The extracts were dried over $\mathrm{Na}_{2} \mathrm{SO}_{4}$, filtered, and concentrated. The resulting oil was purified by column chromatography (7\% EtOAc-hexane) to give the title compound (489 $\mathrm{mg}, 76 \%$ ) (the sample contains a small amount of TBDPSOH): ${ }^{1} \mathrm{H}$ NMR $\left(400 \mathrm{MHz}, \mathrm{CDCl}_{3}\right) \delta 6.00(\delta, J=1.6$ $\mathrm{Hz}, 1 \mathrm{H}), 5.67$ (d, $J=1.6 \mathrm{~Hz}, 1 \mathrm{H}), 4.04-4.94(\mathrm{~m}, 3 \mathrm{H}), 3.90(\mathrm{dt}, J=7.2,3.6 \mathrm{~Hz}, 1 \mathrm{H}), 3.82(\mathrm{dt}, J=$ 11.6, 4.0 Hz, 1H), 3.71-3.69 (m, 2H), 3.62-3.57 (m, 2H), 2.52 (ddd, $J=15.2,10.4,4.4 \mathrm{~Hz}, 1 \mathrm{H})$, $2.40(\mathrm{ddd}, J=15.6,10.8,5.6 \mathrm{~Hz}, 1 \mathrm{H}), 2.06(\mathrm{dd}, J=8.4,4.4,1 \mathrm{H}), 1.96(\mathrm{q}, J=11.6 \mathrm{~Hz}, 1 \mathrm{H})$, 1.84-1.55 (m, 10H), 1.51 (br d, $J=12.0 \mathrm{~Hz}, 1 \mathrm{H}), 0.91(\mathrm{~s}, 18 \mathrm{H}), 0.88(\mathrm{~s}, 9 \mathrm{H}), 0.085$ (s, 3H), 0.08 (s, 3H), 0.07 (s, 3H), $0.062(\mathrm{~s}, 3 \mathrm{H}), 0.056(\mathrm{~s}, 3 \mathrm{H}), 0.05$ (s, 3H). 


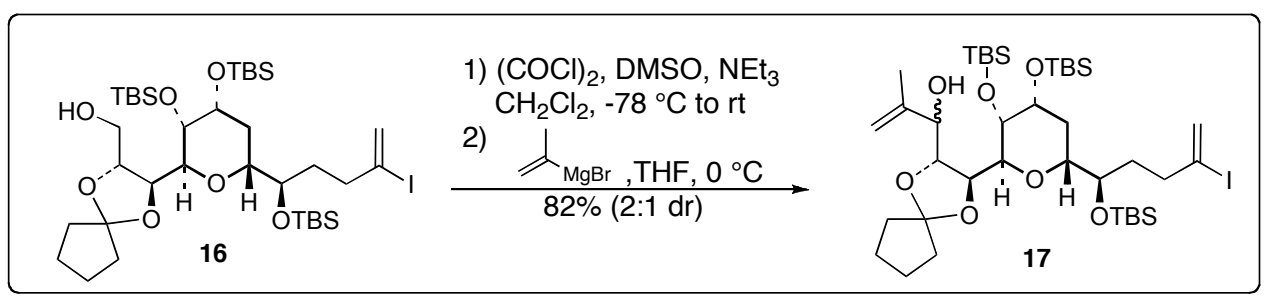

1-((2R,3R)-3-((2S,3S,4R,6R)-3,4-bis(tert-butyldimethylsilyloxy)-6-((R)-1-(tert-

\section{butyldimethylsilyloxy)-4-iodopent-4-enyl)tetrahydro-2H-pyran-2-yl)-1,4-}

dioxaspiro[4.4]nonan-2-yl)-2-methylprop-2-en-1-ol (17). To a $-78{ }^{\circ} \mathrm{C}$ solution of distilled oxalyl chloride $(180 \mu \mathrm{L}, 2.09 \mathrm{mmol})$ in $\mathrm{CH}_{2} \mathrm{Cl}_{2}(1 \mathrm{~mL})$ was added dropwise a solution of dimethyl sulfoxide $(300 \mu \mathrm{L}, 4.18 \mathrm{mmol})$ in $\mathrm{CH}_{2} \mathrm{Cl}_{2}(1 \mathrm{~mL})$. The resulting solution was stirred for $5 \mathrm{~min}$ at $-78{ }^{\circ} \mathrm{C}$. A solution of alcohol $17(1.11 \mathrm{~g}, 1.9 \mathrm{mmol})$ in $\mathrm{CH}_{2} \mathrm{Cl}_{2}(2 \mathrm{~mL})$ was added and the reaction mixture was allowed to stir for $15 \mathrm{~min}$ at $-78{ }^{\circ} \mathrm{C}$. Triethylamine $(0.8 \mathrm{~mL}, 5.7$ mmol) was added, the reaction was warmed to ambient temperature. The reaction mixture was concentrated in vacuo and the resulting white solid was suspended in $\mathrm{Et}_{2} \mathrm{O}$, filtered though Celite, and concentrated in vacuo to give the crude aldehyde as a yellow oil, which was used directly in the subsequent reaction. A $0{ }^{\circ} \mathrm{C}$ solution of the crude aldehyde $(1.9 \mathrm{mmol})$ in THF (5 $\mathrm{mL}$ ) was treated with vinyl magnesium bromide $(3.8 \mathrm{~mL}, 3.8 \mathrm{mmol}, 1 \mathrm{M}$ in THF). The reaction mixture was stirred 15 min at $0{ }^{\circ} \mathrm{C}$, diluted with sat. $\mathrm{NH}_{4} \mathrm{Cl}$ and EtOAc. The aqueous phase was extracted with EtOAc (2x), and the combine organic extracts were washed with brine, dried over $\mathrm{Na}_{2} \mathrm{SO}_{4}$, filtered and concentrated in vacuo. The resulting oil was purified by flash column chromatography (15\% EtOAc-hexane) and the crude oil was used directly in the subsequent reaction. ${ }^{1} \mathrm{H} \mathrm{NMR}\left(400 \mathrm{MHz}, \mathrm{CDCl}_{3}\right) \delta 6.01(\mathrm{~d}, J=1.6 \mathrm{~Hz}, 0.65 \mathrm{H}), 6.00(\mathrm{~d}, J=1.6 \mathrm{~Hz}, .35 \mathrm{H})$, $5.68(\mathrm{~s}, 0.65 \mathrm{H}), 5.67(\mathrm{~s}, 0.35 \mathrm{H}), 5.05(\mathrm{~s}, 1 \mathrm{H}), 4.99(\mathrm{t}, J=1.6 \mathrm{~Hz}, 0.35 \mathrm{H}), 4.97$ (brs, 0.65H), 4.13 $(\mathrm{dd}, J=9.6,5.6 \mathrm{~Hz}, 0.65 \mathrm{H}), 4.06(\mathrm{dd}, J=9.2,5.6 \mathrm{~Hz}, 0.35 \mathrm{H}), 4.03-3.95(\mathrm{~m}, 4 \mathrm{H}), 3.89-3.79(\mathrm{~m}$, $0.65 \mathrm{H}), 3.75-3.70(\mathrm{~m}, 1 \mathrm{H}), 3.66-3.59(\mathrm{~m}, 1.35 \mathrm{H}), 2.80(\mathrm{~d}, J=3.2 \mathrm{~Hz}, 0.35 \mathrm{H}), 2.58-2.53(\mathrm{~m}$, 1H), 2.49-2.34 (m, $1.65 \mathrm{H}), 2.00$ (q, $J=12 \mathrm{~Hz}, 1 \mathrm{H}), 1.95-1.57$ (m, $13 \mathrm{H}), 1.51$ (br d, $J=10.8$ $\mathrm{Hz}, 1 \mathrm{H}), 0.91-0.88(\mathrm{~m}, 36 \mathrm{H}), 0.09-0.04(\mathrm{~m}, 18 \mathrm{H}) ;{ }^{13} \mathrm{C} \mathrm{NMR}\left(125 \mathrm{MHz}, \mathrm{CDCl}_{3}\right) \oint 144.9,144.7$, $138.9,124.9,119.8,119.6,114.2,113.9,112.7,112.1,82.3,82.1,81.7,81.4,76.4,76.3,74.0$, 73.9, 73.8, 73.6, 73.2, 72.5, 72.3, 69.7, 69.6, 68.2, 68.1, 42.2, 42.1, 37.9, 37.7, 37.5, 37.3, 31.4, $31.2,27.6,26.2,25.88,25.85,25.82,23.5,23.4,23.3,23.2,18.8,18.50,18.46,18.2,18.1,18.0$, $4.3,-4.37,-4.41,-4.46,-4.49,-4.6,-4.66,-4.72,-4.8,-4.9$; IR (thin film) $3468,2955,1111 \mathrm{~cm}^{-1}$; HRMS (ESI) calcd for $\mathrm{C}_{39} \mathrm{H}_{75} \mathrm{IO}_{7} \mathrm{Si}_{3} \mathrm{Na} 889.3763 \mathrm{~m} / z(\mathrm{M}+\mathrm{Na})^{+}$; observed $889.3757 \mathrm{~m} / \mathrm{z}$. 


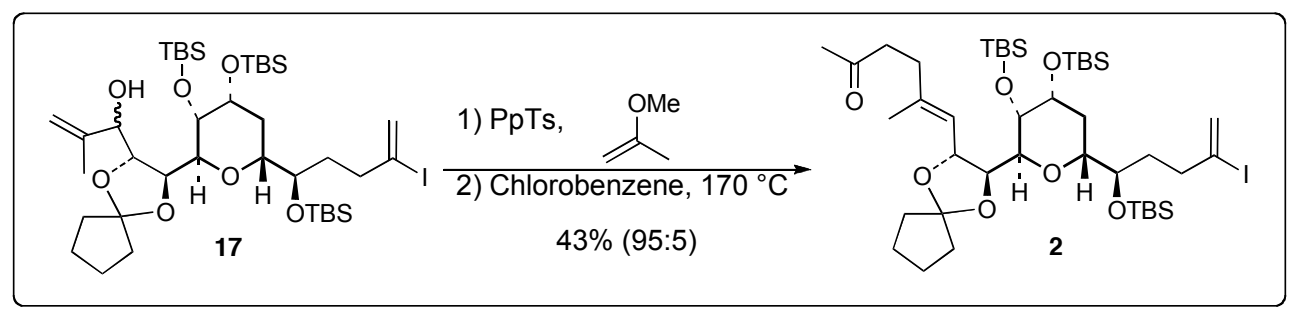

(E)-6-((2R,3S)-3-((2S,3S,4R,6R)-3,4-bis(tert-butyldimethylsilyloxy)-6-((R)-1-(tert-

\section{butyldimethylsilyloxy)-4-iodopent-4-enyl)tetrahydro-2H-pyran-2-yl)-1,4-}

dioxaspiro[4.4]nonan-2-yl)-5-methylhex-5-en-2-one (2). To a solution of allylic alcohol (20 mg, $0.023 \mathrm{mmol})$ in THF $(200 \mu \mathrm{L})$ was added PpTs $(\sim 1 \mathrm{mg})$ and 2-methoxypropane $(17 \mu \mathrm{L}, 0.17$ mmol). The reaction was allowed to stir overnight at $\mathrm{rt}$, then diluted with $\mathrm{Et}_{2} \mathrm{O}$ and sat. $\mathrm{NaHCO}_{3}$. The aqueous phase was extracted with $\mathrm{Et}_{2} \mathrm{O}(\mathrm{x} 2)$ and the combine organic extracts were washed with brine, dried over $\mathrm{Na}_{2} \mathrm{SO}_{4}$, filtered and concentrated in vacuo. The resulting oil was dissolved in dichlorobenzene, a trace amount of $\mathrm{K}_{2} \mathrm{CO}_{3}$ was added, and the reaction was heated to $150{ }^{\circ} \mathrm{C}$ overnight. The solution was then filtered and concentrated in vacuo. The resulting oil was purified by flash column chromatography (10\% EtOAc-hexane) to yield the title compound as a 95:5 E:Z mixture $(9 \mathrm{mg}, 43 \%):[\alpha]_{\mathrm{D}}{ }^{27}=+16.5\left(c 0.9, \mathrm{CHCl}_{3}\right) ;{ }^{1} \mathrm{H}$ NMR $(400$ $\left.\mathrm{MHz}, \mathrm{CDCl}_{3}\right) \delta 6.00(\mathrm{~d}, J=1.2 \mathrm{~Hz}, 1 \mathrm{H}), 5.61(\mathrm{~s}, 1 \mathrm{H}), 5.22(\mathrm{~d}, J=9.2 \mathrm{~Hz}, 1 \mathrm{H}), 4.48(\mathrm{dd}, J=9.2$, $7.2 \mathrm{~Hz}, 1 \mathrm{H}), 4.07(\mathrm{dt}, J=11.6,4.0 \mathrm{~Hz}, 1 \mathrm{H}), 3.93($ br s, 1H), 3.82 (t, $J=7.2 \mathrm{~Hz}, 1 \mathrm{H}), 3.69$ (d, $J=$ $7.2 \mathrm{~Hz}, 1 \mathrm{H}), 3.59-3.51(\mathrm{~m}, 2 \mathrm{H}), 2.59-2.52(\mathrm{~m}, 3 \mathrm{H}), 2.40-2.27(\mathrm{~m}, 3 \mathrm{H}), 2.15(\mathrm{~s}, 3 \mathrm{H}), 1.92(\mathrm{q}, J=$ $12 \mathrm{~Hz}, 1 \mathrm{H}), 1.87-1.57$ (m, 13H), 1.50 (br d, $J=14 \mathrm{~Hz}, 1 \mathrm{H}), 0.91$ (s, 9H), 0.90 (s, 9H), 0.87 (s, 9H), 0.09 (s, 3H), $0.073(\mathrm{~s}, 3 \mathrm{H}), 0.070(\mathrm{~s}, 3 \mathrm{H}), 0.04(\mathrm{~s}, 6 \mathrm{H}), 0.00(\mathrm{~s}, 3 \mathrm{H}) ;{ }^{13} \mathrm{C} \mathrm{NMR}(125 \mathrm{MHz}$, $\left.\mathrm{CDCl}_{3}\right) \oint 207.7,141.5,124.8,122.2,119.0,112.2,80.9,79.2,74.2,72.3,69.7,68.6,42.4,41.8$, $37.5,37.4,33.4,31.1,30.0,27.7,26.2,25.9,25.81,25.77,23.5,23.4,18.5,18.2,18.0,17.2$, -4.2, $-4.3,-4.4,-4.6,-4.7,-4.9$; IR (thin film) 2929, 1721, $835 \mathrm{~cm}^{-1}$; HRMS (ESI) calcd for $\mathrm{C}_{42} \mathrm{H}_{79} \mathrm{IO}_{7} \mathrm{Si}_{3} \mathrm{Na} 929.4071 \mathrm{~m} / z(\mathrm{M}+\mathrm{Na})^{+}$; observed $929.4073 \mathrm{~m} / z$. Olefin geometry confirmed by 1-D NOE analysis:

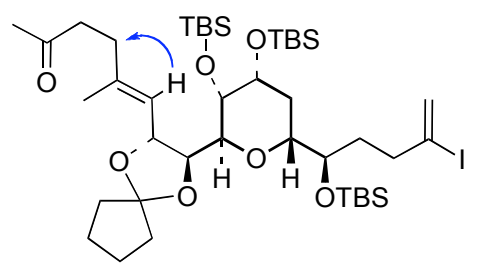




\section{References}

(1) Hicks, J. D.; Flamme, E. M.; Roush, W. R. Org. Lett. 2005, 7, 5509.

(2) Hicks, J. D.; Huh, C. W.; Legg, A. D.; Roush, W. R. Org. Lett., ACS ASAP.

(3) Ohtani, I.; Kusumi, T.; Kashman, Y.; Kakisawa, H. J. Am. Chem. Soc. 1991, 113, 4092.

(4) Still, W. C.; Kahn, M.; Mitra, A. J. Org. Chem. 1978, 43, 2923.

(5) Martinelli, M. J.; Vaidyanathan, R.; Pawlak, J. M.; Nayyar, N. K.; Dhokte, U. P.; Doecke, C. W.; Zollars, L. M. H.; Moher, E. D.; Van Khau, V.; Kosmrlj, B. J. Am. Chem. Soc. 2002, 124, 3578 .

(6) Pereira, A. R.; Cabezas, J. A. J. Org. Chem. 2005, 70, 2594.

(7) Sharma, S.; Oehlschlager, A. C. J. Org. Chem. 1989, 54, 5064-73. 